Gerión. Revista de Historia Antigua

ISSN: 0213-0181

http://dx.doi.org/10.5209/geri.68583

\title{
Las tumbas colectivas en Beocia de los caídos en combate (siglos V-III a.C.)
}

José Pascual ${ }^{1}$

Recibido: 21 de octubre 2019 / Aceptado: 27 de noviembre 2019

Resumen. Este trabajo indaga, a través de los ejemplos disponibles, textuales, arqueológicos y epigráficos, las formas que adoptaron los beocios para enterrar a sus muertos en combate. En Beocia, el enterramiento en el campo de batalla parece haber sido excepcional y se optó por darles sepultura en la necrópolis de la ciudad, habitualmente en una tumba colectiva en forma de túmulo, en un polyandrion. Asimismo, la incineración parece haber sido una práctica muy minoritaria frente al predominio abrumador de la inhumación. Finalmente, los beocios no parecen haber dispuesto ningún epigrama sobre dichos polyandria y prefirieron estelas que recogieran los nombres de aquellos que habían perecido en defensa de la comunidad.

Palabras clave: Grecia antigua; Beocia; muertos en combate; tumbas colectivas.

\section{[en] The Collective Burials in Boeotia of the War Dead (Fifth to Third Centuries B.C.)}

\begin{abstract}
This paper studies the practices used by the Boeotians to bury their war dead through the different sources available: textual, archaeological and epigraphic. In Boeotia, burials in the battlefield seem to have been infrequent, prefering to bury their dead in the necropolis of the city, generally in a collective tumulus, a polyandrion. In addition, cremation seems to be a minority practice against the overwhelming predominance of inhumation. Finally, it seems that the Boeotians did not place any epigram over the polyandria and they preferred to use steles engraving the names of those that had fallen defending the community.

Keywords: Ancient Greece; Boeotia; War Dead; Collective Burials.

Sumario. 1. Introducción. 2. El polyandrion de los tespieos caídos en las Termópilas. 3. Los polyandria de Tespias. 3.1. El polyandrion de la primera mitad del siglo V a.C. 3.2. El polyandrion de los tespieos de la segunda mitad del siglo V a.C. 3.3. El polyandrion de los tespieos del siglo IV a.C. 3.4. El polyandrion del siglo III a.C. 4. El polyandrion de los tanagreos. 5. Los polyandria en Tebas. 5.1. El polyandrion de los tebanos caídos en la conquista de Tebas por Alejandro. 5.2. IG VII 2427: otro polyandrion en la necrópolis tebana. 6 . Un posible polyandrion plateo. 7. El polyandrion de los caídos en la batalla de Queronea (338 a.C.). 8. Conclusiones. 9. Referencias bibliográficas.
\end{abstract}

Cómo citar: Pascual, J. (2020): Las tumbas colectivas en Beocia de los caídos en combate (siglos V-III a.C.), en Gerión 38/1, 11-36.

Universidad Autónoma de Madrid.

E-mail: jose.pascual@uam.es 


\section{Introducción ${ }^{2}$}

Setecientos años después de que tuviera lugar el combate de Maratón, Pausanias se acercó a la llanura que fue campo de batalla y buscó, en vano, las tumbas de los medos, a pesar de que los atenienses le aseguraban que los habían enterrado. En su indagación, el Periegeta llega a afirmar que: "era un deber piadoso y absolutamente

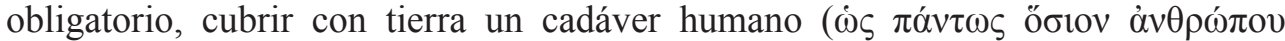

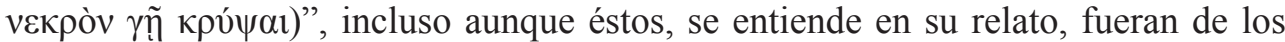
enemigos muertos, griegos o bárbaros, y aun cuando no hubieran sido reclamados por los vencidos. ${ }^{3}$

Como indica Pausanias, dar tierra a un cadáver se concebía, en primer lugar, como un deber religioso, hosios, es decir, piadoso, que agradaba a los dioses y obedecía a sus designios. Hosios no sólo significaba aquello que estaba permitido o que complacía a los dioses, sino que conllevaba también la noción de pureza, ya que la impureza - mysos, miasma- de los cuerpos en descomposición y que no habían recibido el rito de enterramiento debido, repugnaba y ofendía antes a los dioses que a los hombres. ${ }^{4}$ El comportamiento piadoso hacia los fallecidos libraba a la familia y también a toda la comunidad de la contaminación miasmática que se asociaba con el cuerpo muerto y que podía ser provocada por los mismos dioses. ${ }^{5}$ Esto es, en las relaciones que se entablaban entre los hombres, hosios indicaba un tratamiento apropiado del prójimo, aunque éste fuera un difunto, y encerraba también un deber para con los dioses, pues éstos podían castigar a los vivos por su conducta impía hacia los cadáveres. Y así, por ejemplo y en un sentido contrario, Lisias recuerda a los jueces atenienses que los "Treinta Tiranos" -los oligarcas de 404/3- privaron a sus víctimas del entierro habitual, "sin dejarles siquiera que recibieran las honras

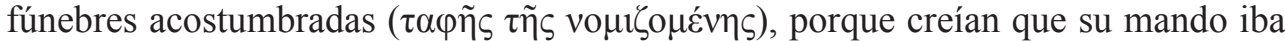

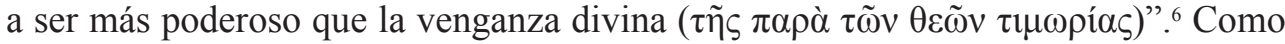
vemos, Lisias emplea aquí el concepto de ta nomizomena, que podemos interpretar como el carácter tradicional de los ritos. Puesto que la religión griega carecía de un credo de revelación divina, la comunidad apelaba a los ritos tradicionales -es decir, a la realización correcta de los rituales en el tiempo y lugar correctos-como una forma de apartar la venganza divina. ${ }^{7}$ Esto mismo lo expresa Isócrates afirmando que la piedad consiste en realidad "en no cambiar nada de aquello que nos han transmitido los antepasados", 8 y también el propio orador, en la misma concepción expuesta por Lisias, indica que el hecho de que los cadáveres permanezcan insepultos era una desgracia peor para aquellos que impedían el enterramiento que para quienes no lo obtenían. ${ }^{9}$ En suma, este repudio que causaba que los muertos quedaran sin

Todas las fechas son a.C. a no ser que se indique lo contrario.

Paus. 1.32.5. Sobre la obligación de dar sepultura a los muertos: Parker 1996, 43-48.

Bruit Zaidman - Schmitt-Pantel 2002, 8-13; Bremmer 2006, 22; Burkert 2007, 357-360. Acerca de la contaminación miasmática puede consultarse Parker 1996. Sobre la pureza ritual, por ejemplo, Bendlin 2007, 178-180. En general sobre hosios: Peels 2015.

Parker 1996, 35-43.

Lys. 12.96.

Deacy 2007, 222; Hedrick 2007, 283.

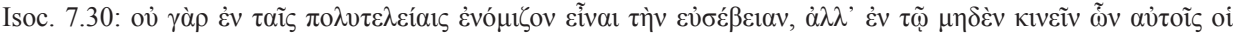
$\pi \rho \gamma_{\gamma}$ ovoı $\pi \alpha \rho \varepsilon ́ \delta o \sigma \alpha v$.

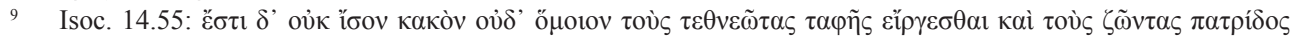

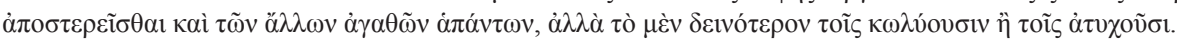


enterramiento implicaba tanto a los dioses como a toda la comunidad humana y no sólo a un individuo concreto. Constituía un sentimiento común a todos los griegos universalmente reconocido y formaba parte de la costumbre helénica, del 'E $\mathrm{A} \lambda \eta$ ๆvikòs vó $\mu$ os, que los cadáveres recibieran sepultura, ya que, además, no se podía entrar en el Hades sin un entierro y los ritos adecuados que acompañaban al funeral. ${ }^{10}$

De entre todos los muertos, se debía tener un especial cuidado en dar sepultura a los caídos en combate, ${ }^{11} \mathrm{y}$ era tan extraordinario que se incumpliera esta costumbre piadosa que los autores antiguos no dejan de reseñarlo cuando tal cosa sucedía. ${ }^{12}$ Por introducir únicamente dos testimonios casi simultáneos, Tucídides dice, con motivo de la campaña en Sicilia en 413, que, después de la derrota ateniense ante los siracusanos, en su intento de romper el bloqueo marítimo al que éstos les tenían sometidos, los atenienses no recogieron los cadáveres ni solicitaron tregua para darles sepultura ${ }^{13}$ y que, cuando emprendieron la retirada, abandonaron tras ellos a los cadáveres insepultos, a los enfermos y a los heridos. ${ }^{14}$ Recobrar los cadáveres de los muertos en combate y enterrarlos en el campo de batalla o transportarlos a la patria era esencial también para mantener la moral, la camaradería de los combatientes y la cohesión de las unidades, y tranquilizaba no sólo a los propios soldados sino, además, a la comunidad políada en su conjunto. Resultaba completamente anómalo el hecho de que los soldados no tuvieran una sepultura asegurada o que los vencedores no devolvieran los cadáveres de los vencidos, una costumbre que el mismo mito sancionaba. ${ }^{15}$ En consecuencia, dejar los cadáveres insepultos en el campo de batalla no sólo era contrario a la costumbre y a la piedad helénicas, sino que se consideraba también una práctica bárbara, una insensibilidad que horrorizaba a los griegos. ${ }^{16}$ Así, tras la derrota de los gálatas de Brenno en las Termópilas, acaecida en el año 279, Pausanias afirma, con una mezcla de horror y extrañeza, que "después de la batalla, los galos no enviaron ningún heraldo con la solicitud de permiso para recoger a sus muertos y consideraron indiferente que fueran dejados ahí y fueran devorados por las bestias salvajes y las aves". ${ }^{17}$

Sin embargo y como es obvio, dentro de la regla común griega, la costumbre de enterrar a los muertos en combate podía experimentar diferencias y variaciones; en ellas precisamente vamos a incidir, tomando como objeto de estudio un caso concreto, las tumbas colectivas de los ciudadanos caídos en combate en la Beocia de la época clásica y de principios del Helenismo (Fig. 1).

\footnotetext{
Lys. 2.9. Véase Hom. Il. 23.69-74.

Arrington 2010a, 1-16.

Para los muertos en combate sin enterramiento: Pritchett 1985, 235-241.

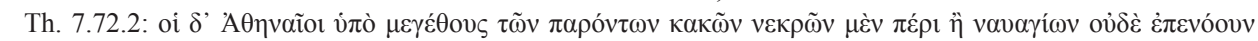

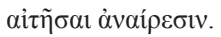

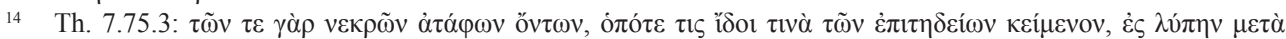

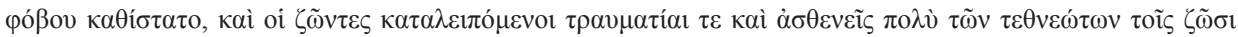

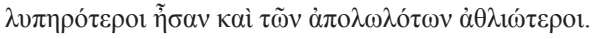

15 Pritchett 1985, 96; Krentz 2007, 212. Sobre los mitos acerca de la devolución de los cadáveres en los casos, por ejemplo, de Heracles y Teseo: Plu. Thes. 29.4; Ael. VH 12.27; Pritchett 1985, 97.

16 Véase, por ejemplo, Sourvinou-Inwood 1995, 123-124.

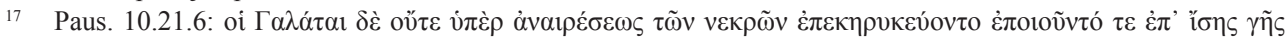

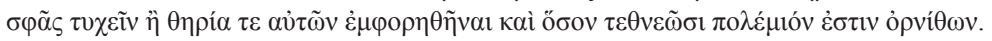




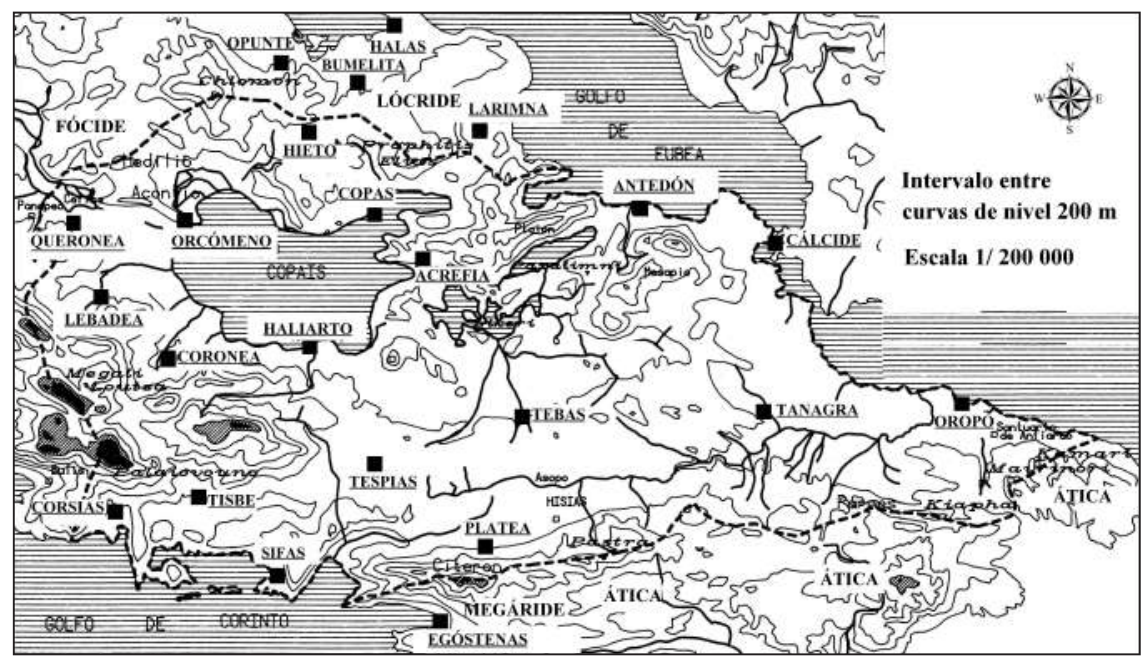

Fig. 1. Beocia en época clásica (J. Pascual).

\section{El polyandrion de los tespieos caídos en las Termópilas}

El primer enterramiento colectivo de muertos beocios en combate que conocemos del siglo $\mathrm{V}$ es precisamente el polyandrion de los griegos en las Termópilas, donde los tespieos cayeron combatiendo junto a los espartiatas en la Puerta Media. Las circunstancias de su muerte nos son bien conocidas gracias al relato de Heródoto sobre la resistencia de los griegos en el Paso, liderados por Leónidas. De este modo, en el último día de los combates, los tespieos y los tebanos permanecieron junto a los espartiatas, los primeros, según Heródoto, ${ }^{18}$ se quedaron por voluntad propia y se negaron a retirarse, mientras que los tebanos fueron obligados por la fuerza en calidad de rehenes. Una vez que los persas rodearon a los griegos, los tebanos huyeron y los espartiatas y los tespieos se retiraron a la colina que estaba cerca del Paso, la de Colonos (Fig. 2). Aquí los tespieos hallaron la muerte al lado de los espartiatas. ${ }^{19}$

De acuerdo con Heródoto, los griegos fueron sepultados en el mismo lugar en el que cayeron, al igual que quienes murieron antes de que se retiraran los que habían sido autorizados por Leónidas..$^{20}$ El historiador de Halicarnaso añade que, al objeto de que los soldados de la flota los vieran, Jerjes mandó reunir a todos los griegos

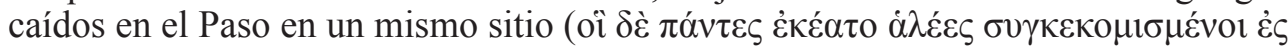
$\tau \hat{\imath} v \tau$ ¿ò $\chi \omega \rho i ́ o v)$ y que éstos alcanzaban la cifra de cuatro mil. ${ }^{21}$ Es decir, los cadáveres de los griegos fueron reunidos todos juntos, tanto aquellos que habían caído aledaños al muro como quienes perecieron en la colina de Colonos; entre ellos figuraban no sólo tespieos y lacedemonios, sino también hilotas. No sabemos si, una vez que

Hdt. 7.222.

Hdt. 7.225-226.

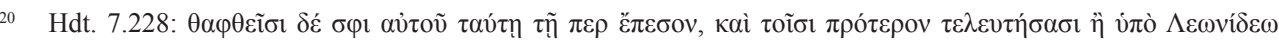

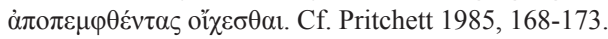

21 Hdt. 8.25.1-2. 
tuvo lugar el engaño de presentar a los soldados de la flota los muertos griegos frente a sólo mil caídos propios, los persas enterraron a los griegos o los dejaron insepultos. Se ha pensado que los enterraron en una fosa común, como debieron de hacer con los caídos de su ejército. ${ }^{22}$ En todo caso, después de la guerra, los griegos parecen haber mantenido o excavado una única tumba en la que debieron recoger a todos los caídos, incluyendo los hilotas, quizás entonces ya irreconocibles. En apoyo de esta hipótesis, Estrabón menciona la existencia de un único polyandrion en las Termópilas, que constituiría el único monumento o memorial que se alzaba en el Paso y donde estarían sepultados todos los que murieron allí. ${ }^{23}$

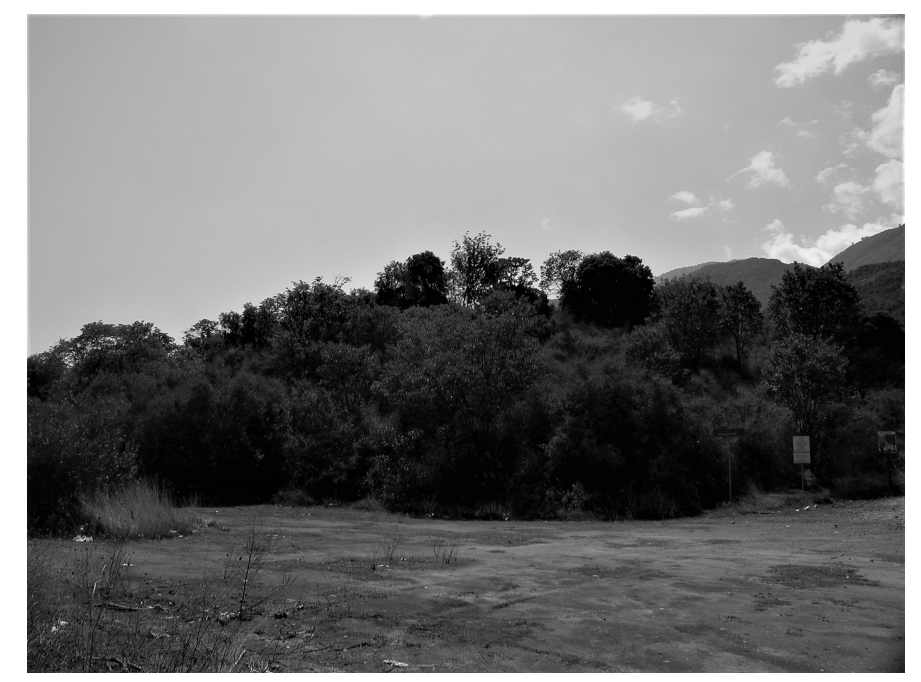

Fig. 2. La colina de Colonos, la última posición de los espartiatas y tespieos en las Termópilas (J. Pascual).

Después de la guerra y una vez que los griegos tuvieron acceso a las Termópilas, todos los combatientes, con la sola excepción de los tebanos, recibieron el tratamiento de héroes y la fosa común fue honrada. Fue entonces cuando se elevó un túmulo y se erigió la estatua de mármol de un león en honor a Leónidas en la colina que se encontraba a la entrada del paso. El león era símbolo del poder real; así lo recuerda Heródoto en varias ocasiones ${ }^{24}$ y aludía también al propio nombre de Leónidas. Sobre el túmulo se dispusieron, además, una serie de estelas sobre las que se inscribieron epigramas que recordaban a los que allí perecieron. Heródoto cita tres de ellos: ${ }^{25}$ un epigrama aludía a los peloponesios en su conjunto, ${ }^{26}$ otro hacía referencia a los espartiatas en particular, ${ }^{27}$ y el último estaba dedicado

22 Cf. Wade-Gery 1933, 72: "Doubtless Leonidas and the other dead were ultimately buried". Heródoto (8.24) indica que Jerjes había enterrado en varias fosas a dicienueve mil caídos de su ejército, dejando únicamente mil a la vista. Previsiblemente éstos también serían enterrados después.

23 Str. 9.2.1.

24 Hdt. 1.84.3, 5.92 b3, 6.131.2.

25 Hdt. 7.228.1-4.

26 Cf. Lycur. Leocr. 109; Diod. 11.33.2; Aristid. 49.380; Ant. Pal. 7.248.

27 Lycur. Leocr. 109; Diod. 11.33.2; Str. 9.4.16; Ant. Pal. 7.277, 282. 
individualmente al adivino Megistias. Heródoto asegura que fueron los Anfictiones quienes honraron a los caídos con epitafios y estelas, ${ }^{28}$ mientras que Simónides de Ceos honró individualmente a Megistias, con quien estaba unido por vínculos de hospitalidad. Esto explicaría que Megistias fuera la única persona mencionada por su nombre en las estelas. Debemos pensar, por lo tanto, que, en una reunión anfictiónica posterior a la guerra, en Antela y mediante un decreto anfictiónico, se decidió la construcción de un memorial a los caídos y, posiblemente, no sólo elevar las estelas, sino también la estatua del león.

Estrabón dice que, cerca del polyandrion de los griegos en las Termópilas, se elevaban cinco estelas, la primera de las cuales hacía referencia a los opuntios, como metrópolis de los locrios. ${ }^{29}$ Es evidente que esta estela conmemoraba a los mil locrios que combatieron en el Paso y debió de ser sufragada previsiblemente por los opuntios, aunque quizá este autor confunde locrios orientales y opuntios, pero en lo que a nosotros nos interesa recoger aquí, tendríamos identificadas cuatro de las cinco estelas que fueron colocadas en las Termópilas.

Esteban de Bizancio (s.v. $\Theta \varepsilon ́ \sigma \pi \varepsilon 1 \alpha$ ), refiriéndose a la ciudad de Tespias, menciona un epigrama que honraba a los tespieos caídos en las Termópilas y que fue compuesto por Filiadas de Mégara:

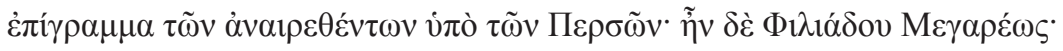

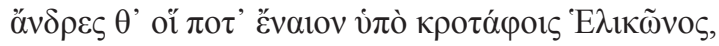

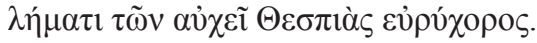

Un epigrama de los que fueron muertos por los persas: fue (obra) de Filiadas de Mégara:

Del espíritu de aquellos hombres que una vez moraron en las laderas del Helicón, la espaciosa Tespias se enorgullece.

Se ha alegado en contra de este testimonio que la fuente que utiliza Esteban de Bizancio nos es desconocida, que Filiadas parece haber sido un oscuro poeta de una ciudad pequeña, que el epigrama quizás no esté completo y que no parece haber sido compuesto para su inscripción en un epitafio sobre una estela. ${ }^{30}$ Todo ello no parece suficiente para desechar la noticia de Esteban de Bizancio. Si los peloponesios, locrios y espartiatas tenían un epigrama en las Termópilas, parece muy plausible que también lo tuvieran los tespieos, que se habían destacado en la defensa del Paso, que habían permanecido junto a los espartiatas una vez que el resto del ejército se había retirado, y que habían perecido al lado de Leónidas y los suyos. En este sentido, resultaría bastante extraño que los tespieos fueran los únicos de entre todos los griegos que no tuvieran una estela propia en las Termópilas. Además, si, como afirma Estrabón, se dispusieron cinco estelas sobre el polyandrion de las Termópilas, nos quedaría una quinta por identificar que podría corresponder a los tespieos sin contradicción alguna con el testimonio de Esteban de Bizancio. Tespias compartía frontera con Mégara y es evidente que los poetas megareos podían ser bien conocidos por los tespieos, lo suficiente como para que estos últimos encargaran a Filiadas componer el epitafio

Hdt. 7.228.4.

Str. 9.4.2.

Hiller 1926, 19; Page 1981, 78-79; Wade-Gery 1933, 76: "what perhaps is part of the real epitaph of the Thespians who died at Thermopylai" (cursiva en el original). 
que honraba a sus conciudadanos caídos en las Termópilas. En ello incidiría la importancia de la propia tradición poética megarea representada, por ejemplo, por Teognis, un poeta de mediados del siglo VI y quizá todavía vivo en el momento de la invasión persa. ${ }^{31} \mathrm{Si}$ hubiera fallecido antes de la Segunda Guerra Médica, se ha pensado que unos versos incluidos en su obra y que hacen referencia precisamente a la expedición de Jerjes pudieran atribuirse quizás a otro poeta megareo, puede que al mismo Filiadas, ${ }^{32}$ que no sería tan desconocido como se ha pensado.

Como decimos, Tespias decidió, de la misma manera que todos los demás griegos, que los muertos en la defensa de las Termópilas permanecieran sepultados en el Paso, allí donde cayeron, junto a sus camaradas con los que habían compartido un mismo destino. El polyandrion de los caídos en las Termópilas aunaba la costumbre ancestral griega de dar sepultura a los muertos con la tradición homérica de enterrar a los muertos en el campo batalla. ${ }^{33}$ De hecho, la construcción de un túmulo que albergara a todos los caídos en una misma batalla tenía su paradigma en los poemas homéricos, en los funerales de Héctor, por ejemplo, ${ }^{34}$ hábito que se extendía no sólo a los héroes individuales de los poemas sino a todos los combatientes. ${ }^{35}$ De este modo, los tespieos que habían combatido en las Termópilas se asimilaban a los héroes homéricos, con sus tumbas tumulares que se asemejaban a las que se incluían en las viejas sagas de héroes, y que transmitían una serie de códigos simbólicos de valor y sacrificio que todos comprendían. Las tumbas colectivas de los caídos en combate enlazaban, así, con los héroes de la Guerra de Troya. Como Aquiles y el resto de sus compañeros muertos, los que perecieron en las Termópilas cayeron y fueron enterrados de la misma manera que aquellos helenos que navegaron y combatieron en Troya, contra Asia.

El polyandrion de las Termópilas refleja, asimismo, la integración y difusión de los valores propios del cuerpo cívico que supone la polis. En él se unen la costumbre griega, los reflejos de la épica y también las nuevas ideas impulsadas por los sectores no aristocráticos de la ciudadanía y el desarrollo del combate hoplítico. Por consiguiente, frente a los paladines aristocráticos de la épica, los ciudadanos morían ahora en defensa de su comunidad, de la patris, en una nueva excelencia que se alcanzaba en el combate colectivo, y que expresa, por ejemplo y con toda claridad, Esquilo en el peán con el que los griegos entran en combate en Salamina. ${ }^{36}$ La tumba colectiva que recogía a todos los caídos en una misma guerra suponía, de hecho, la generalización de las prácticas guerreras aristocráticas y de los valores homéricos que alcanzaban ahora a toda la comunidad y, de manera especial, a quienes habían perecido protegiéndola, en un nuevo heroísmo colectivo introducido por la polis que los situaba en un plano superior al común de los mortales y les confería una fama inmortal.

El polyandrion de las Termópilas creaba también un paisaje heroico, un territorio en el que los héroes una vez habían estado vivos y habían florecido. La fosa común

\footnotetext{
Bowie 1997; Selle 2008.

Theog. 773-782. Cf. Bowie 2009, 106.

Hom. Od. 1.236-240; Pritchett 1985, 94-97. Sobre el funeral debido a los muertos y el vocabulario de los poemas acerca de las tumbas: Sourvinou-Inwood 1995, 109-110, 134-135.

Hom. Il. 23.784-795.

Hom. Il. 7. 412-432.

A. Pers. 402-405: “Adelante, hijos de los griegos, libertad a la patria. Libertad / a vuestros hijos, a vuestras mujeres, los templos de / los dioses de vuestra estirpe y las tumbas de vuestros / antepasados. Ahora es el combate por todo eso" (trad. Perea Morales, BCG 1993, adaptada).
} 
en forma de túmulo, como temenos sagrado y heroico, delimitado por un muro perimetral o peribolos, que se señalaba con la estatua de un león y sobre el que se alzaban estelas, definió también el tipo de tumba colectiva característica en Beocia para enterrar a los caídos en combate. Ética, psicológica y arquitectónicamente constituyó su modelo.

\section{Los polyandria de Tespias}

\subsection{El polyandrion de la primera mitad del siglo $\mathrm{V}$ a.C.}

Antes del año 1880, fecha en que tenemos noticia por primera vez de ella, fue hallada en Ellopia una inscripción que se encuentra ahora depositada en el Museo de Tebas con el número de inventario 1967. Dicho epígrafe fue estudiado por Keramopoullos ${ }^{37}$ y publicado asimismo en IG VII 1889 et add. y en Inscriptions de Thespies (IThesp) $\mathrm{n}^{\mathrm{o}} 484$.

Se trata de una columna de piedra caliza blanca, de $89 \mathrm{~cm}$ de alto y $28 \mathrm{~cm}$ de diámetro con letras en alfabeto epicórico, que recoge un listado de caídos en combate. Es muy posible que dicha inscripción se alzara originalmente en la necrópolis de la antigua Tespias, que se extendía unos 5-6 km al noreste de la actual Ellopia.

$1 \quad \Theta \varepsilon \sigma[\pi] 1 \varepsilon[\varsigma]$

$\sigma \varepsilon \tilde{\varepsilon} \alpha \tau \underline{\jmath} \delta[\varepsilon]$

$\dot{\alpha} v \varepsilon \dot{\varepsilon} \theta \varepsilon \alpha v^{*}$

A $\theta \alpha \mu \alpha v i ́ o v$

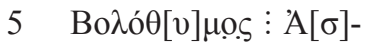

$\kappa \lambda \alpha \pi i ́ o v$

To $\lambda \mu i ́ \delta \alpha \varsigma \zeta$

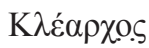

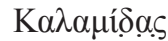

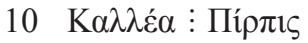

K $\lambda \varepsilon \dot{0}$ : K K $\lambda \dot{o v}$

$\sum \dot{\imath} \lambda \lambda \varepsilon$ : K $\lambda \dot{\varepsilon} \sigma i \pi \pi \circ \varsigma$

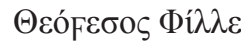

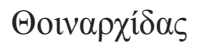

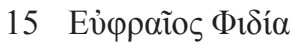

Avtıxapĩvos

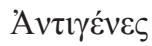

A $A \dot{\varepsilon} \lambda \lambda \imath \chi \propto \varsigma$

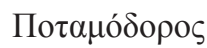

37 Keramopoullos 1936, 23, no 190. 
La columna se elevaba sobre una tumba colectiva, que es denominada sema (línea 2), y que conservaba los restos de los tespieos muertos (línea 1) -unos veinte o veintiuno- en un enfrentamiento cuyo nombre no se menciona. El estilo de las letras parece ser anterior al polyandrion que se relaciona con la batalla de Delio (véase el apartado siguiente, 3.2), pero no parece, quizás, tan antiguo como para relacionarla con las Termópilas. En todo caso, como vimos, los tespieos caídos en las Termópilas fueron enterrados donde cayeron, junto a la entrada del paso. Además, a través de Heródoto, ${ }^{38}$ conocemos el nombre del comandante tespieo caído en las Termópilas, Demófilo, y el de uno de los combatientes, Ditirambo, nombres que no aparecen entre los listados en la estela; por otro lado, la cifra de veinte o veintiuno resulta muy baja para el número, más que considerable, de los setecientos enviados a las Termópilas, muchos de los cuales debieron de perecer junto a los espartiatas. Por lo tanto, los tespieos enterrados en este polyandrion deben de haber muerto en otra de las grandes batallas del siglo, lo suficientemente importante para justificar un enterramiento colectivo, como Enófita (456) o Coronea (446). ${ }^{39}$

Pero más allá de la batalla concreta, resulta evidente que, junto a la costumbre de enterrar a los muertos en el campo de batalla, también era correcto darles sepultura en la necrópolis de su propia patria, lo que implicaba varias acciones rituales, una doble prothesis o el cuidado de los muertos, sobre el campo de batalla y en la patria, y una ekphora o traslado de los cadáveres desde el campo de batalla a la necrópolis de la ciudad. ${ }^{40}$ De acuerdo con Aristóteles, en el caso de Atenas el arconte polemarco se encargaba de los funerales de los caídos en batalla. ${ }^{41}$ Tucídides describe esta ceremonia. ${ }^{42}$ Durante los tres días anteriores a la sepultura, los restos se velaban en una tienda levantada con este propósito. En el día del entierro, se trasladaban los cadáveres al cementerio en diez larnakes de madera de ciprés, uno por cada tribu. Cualquiera podía participar en la procesión. Se pronunciaba un discurso fúnebre, se inscribían sobre una estela los nombres de los muertos, y se llevaban a cabo sacrificios rituales.

Los caídos tespieos no fueron enterrados en Tespias en tumbas individuales al lado de sus familiares, sino que para ellos se elevó un túmulo o sema, una tumba colectiva. En este polyandrion tespieo se dispuso también una estela que, frente a los muertos en las Termópilas, no recogía ningún epigrama sino los nombres de los caídos. La pira, las ofrendas depositadas en el túmulo, el enterramiento colectivo y los nombres inscritos en las estelas sugieren prácticas rituales tespieas parecidas a las atenienses. ${ }^{43}$ En todo caso, el enterramiento de los tespieos habría sido, evidentemente, un acto políado, público, organizado por los magistrados de la polis.

38 Hdt. 7.222-228.

39 En el caso de la batalla de Platea, que podría ser también objeto de este túmulo, Heródoto (9.28) no menciona que combatieran hoplitas tespieos y sólo refiere que comparecieron mil ochocientos infantes ligeros, desprovistos de armamento pesado (9.30), lo que puede reflejar la pérdida de la mayoría de su ejército hoplítico en las Termópilas (véase Hanson 1999, 208-209). Aunque no se puede descartar completamente, no es probable que se elevara una estela para conmemorar únicamente a infantes ligeros, los sectores por debajo del censo hoplítico, en la Beocia marcadamente aristocrática de las Guerras Médicas.

40 Cf. Paus. 1.29.4; $I G$ VII 1888 en la misma Tespias, o $I G \mathrm{~V}^{2} 1.28$ en Epidauro en 148. También podían ser trasladados y enterrados en territorio amigo, como el caso de Lisandro, muerto en 395 en Beocia bajo los muros de Haliarto y sepultado en Panopeo de Fócide, una ciudad aliada (Plu. Lys. 29.2-3). Sobre los rituales de la prothesis y ekphora puede consultarse Kurtz - Boardman 1971, 112-121; Pritchett 1985, 102-106.

41 Arist. Ath.Pol. 58.

42 Th. 2.34. Véase Clairmont 1983, 7-15.

43 Sobre las estelas atenienses: Kurtz - Boardman 1971, 123-127. 
A partir de este polyandrion es posible pensar, por lo tanto, que los tespieos tuvieron una forma de honrar a los caídos en combate similar a la que conocemos en Atenas. Así, los atenienses dispusieron en torno al año 500 en la propia Atenas de un lugar de enterramiento para los caídos en combate, junto a sus hombres célebres, el demosion sema, el cementerio público. ${ }^{44}$ Se trataba de un área extensa que se disponía en el lado noroeste de la ciudad, en el Cerámico, tras la Puerta del Dipylon, en el camino de la Academia. Podríamos estar, en suma, ya en la primera parte del siglo $\mathrm{V}$ ante un demosion sema tespieo, similar al ateniense y quizás de influencia ática, un lugar en el que reposaban juntos todos aquellos que habían dado su vida por la comunidad. Esta hipótesis podría verse corroborada por lo que conocemos de las demás tumbas colectivas tespieas.

\subsection{El polyandrion de los tespieos de la segunda mitad del siglo $\mathrm{V}$ a.C.}

Entre octubre y noviembre de 1882, Stamatakis encontró en la necrópolis extramuros de la ciudad antigua de Tespias ocho estelas $(\mathrm{A}-\mathrm{H})$ y un pequeño fragmento de una novena (I) que listaban los nombres de más de cien tespieos muertos en combate. ${ }^{45}$ Estas estelas no fueron halladas in situ, sino bordeando un camino que se localizaba a unos $2,5 \mathrm{~m}$ al norte de donde fue excavado un polyandrion, sobre el que se alzaba también la estatua de un león, que se encontró en estado fragmentario. Stamatakis supuso que las estelas fueron originalmente dispuestas en este polyandrion a ambos lados del león.

Esta tumba colectiva estaba delimitada, en la parte del camino, por un muro que se excavó en una extensión de $32 \mathrm{~m}$ y que contaba con un metro de anchura. Evidentemente dicho muro, además de cerrar la tumba por este lado, cumplía también la función de contrafuerte con el fin de soportar la tierra del túmulo. En el centro de este muro perimetral se hallaron precisamente los fragmentos de la estatua de león que debía de elevarse en el mismo. Perpendicular al muro del león, en el lado oriental, se excavó también otro muro de $23 \mathrm{~m}$ que remataba la tumba por este lado. ${ }^{46}$

Las estelas están todas ellas realizadas en el mismo tipo de piedra, una caliza local, y presentan la misma disposición, con unas medidas de 1,$05 ; 0,42-045 ; 0.16$ (Fig. 3) ${ }^{47}$ Sin embargo, a pesar de su homogeneidad y de acuerdo con el estilo de las letras, los epígrafes parecen distribuirse en dos grupos en los que las estelas CDEFG parecen más antiguas, mientras que el grupo ABHI sería más moderno. Estas diferencias se han tratado de explicar de varias maneras: quizás los caídos tespieos procedieran de dos batallas diferentes que se inscribieron, por tanto, en momentos distintos, o quizá algunas de ellas fueron regrabadas porque se pudo producir algún deterioro posterior, por ejemplo, tras la toma de la ciudad por los tebanos en $423 .{ }^{48}$ Es posible también que ambos grupos de inscripciones fueran tallados por dos lapicidas o dos talleres distintos, una práctica que conocemos en la epigrafía ática. ${ }^{49}$

\footnotetext{
Cf. Clairmont 1983, 29-45; Pritchett 1985, 103; Arrington 2010a, 17-83, y 2010 b.

45 Stamatakis 1883, 71-72; IG VII 1888, Museo de Tebas, $\mathrm{n}^{\circ}$ inv. 2016 a 2023 (la estela I sin $\mathrm{n}^{\mathrm{o}}$ de inventario); IThesp $\mathrm{n}^{\circ} 485$.

46 Sobre este polyandrion véase fundamentalmente Schilardi 1977.

47 Stamatakis 1883, 71-72; Ure 1913, 24, pl. 11.4; Keramopoullos 1920, 18-20; Ridder 1922, 253-259, figs. 33-36; Austin 1938, 74; Jeffery 1961, 94-95, nº 19a, pl. 10; Clairmont 1983, 231-234.

$48 \quad$ Th. 4.133.1.

49 Cf. SEG 10.409; Museo Epigráfico no inv. I 953 a-e, una misma estela de caídos en combate atenienses de la primera mitad del siglo $\mathrm{V}$, en la que las líneas 45 a 53 parecen haber sido inscritas por distintas manos (Bradeen 1964, 17-18, 20).
} 


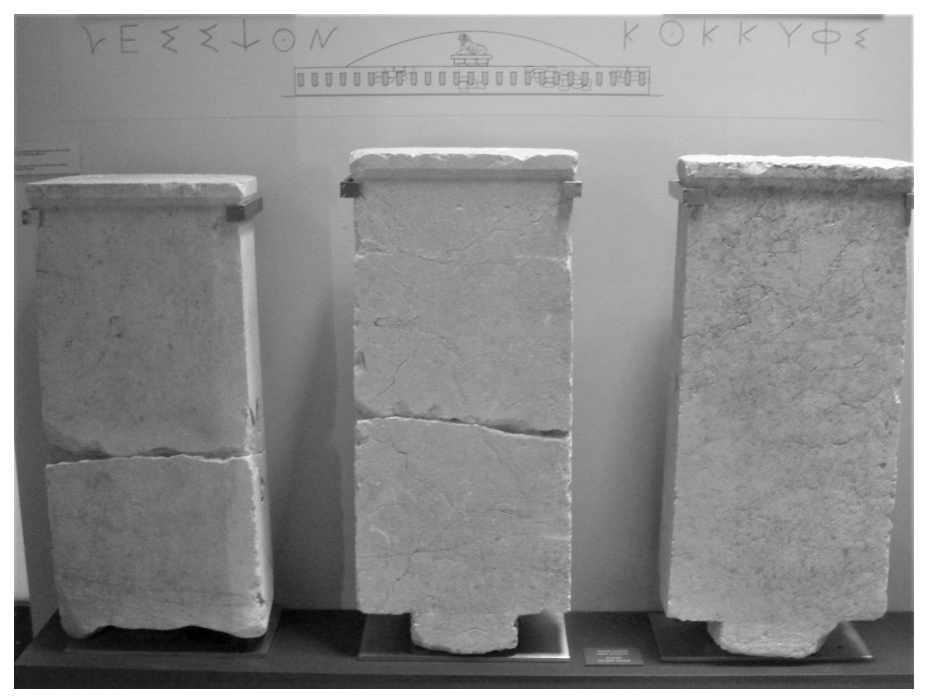

Fig. 3. Museo de Tebas. El polyandrion de los tespieos (J. Pascual).

Las estelas conservan los nombres de 101 tespieos, siete epígrafes tienen inscritos doce nombres, la estela $\mathrm{G}$ lista diez nombres y la I, siete. Sin embargo, el tamaño de la tumba sugiere un número mayor de 101. Si, como verosímilmente pretendió Stamatakis, las estelas fueron dispuestas a lo largo del muro que flanqueaba el camino, a ambos lados del león, hubiera existido espacio al menos para unas veinticinco estelas que podrían recoger unos trescientos nombres como mínimo, un número extraordinario para una ciudad de la importancia relativa de Tespias, por lo que esta tumba debe relacionarse con las pérdidas, y cuantiosas, de una batalla más que notable. Platon y Feyel ${ }^{50}$ la relacionaron con la batalla de Delio, librada en 424 entre beocios y atenienses, del mismo modo que Clairmont. ${ }^{51}$ En dicha batalla, Tucídides relata que los atenienses se impusieron al ala izquierda beocia y atacaron principalmente a los tespieos, puesto que, al batirse en retirada el resto de dicha ala, éstos quedaron cercados en un espacio reducido y muchos de ellos fueron aniquilados en una lucha cuerpo a cuerpo. ${ }^{52}$ Tucídides señala que incluso algunos atenienses, confundidos en la maniobra de cerco, perecieron también a manos de sus propios compatriotas. ${ }^{53}$ En la batalla cayeron algo menos de quinientos beocios y más de mil atenienses. ${ }^{54}$ Indudablemente la mayor parte de los muertos beocios debía de contarse en el ala izquierda derrotada y la mayoría serían tespieos, ${ }^{55}$ como da también a entender más adelante Tucídides, quien asegura que en la batalla con los atenienses "pereció la flor

Platon - Feyel 1938, 150: "liste de Thespiens tués sans doute à Delion, en 424".

Clairmont 1983, 233. Igualmente, Frazer - Ronne 1958, 36. Véase también Pritchett 1985, 132-133.

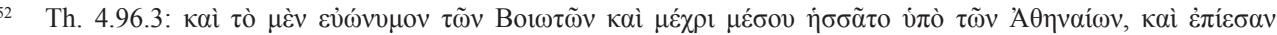

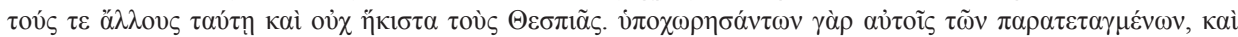

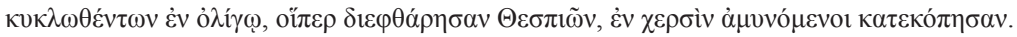

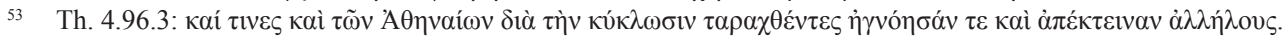

54 Th. 4.101.1. Cf. Diod. 12.70.4: los beocios caídos no eran más de quinientos, mientras que las bajas del lado ateniense fueron muy superiores.

55 Hanson 1999, 211-212. 
de la juventud de la ciudad (de Tespias)" ${ }^{56}$ Una masacre que justificaría la presencia en la necrópolis tespiea de un extenso túmulo que acogiera más de cien muertos y quizás incluso en torno a trescientos. Según Tucídides, luego de la batalla, los beocios erigieron un trofeo, recogieron los muertos y despojaron a los enemigos. ${ }^{57}$ De este modo, desde Delio, los tespieos habrían recogido a los cadáveres de sus muertos en combate y los habrían trasladado a la ciudad, que estaba a más de $50 \mathrm{~km}$ de distancia.

En la línea 10 de la estela B figura el nombre de Polínico, del que se dice expresamente que era olimpiónico. ${ }^{58}$ Este tespieo fue vencedor de la lucha juvenil en la Olimpiada $83^{\mathrm{a}}$ del año 448 , así que la batalla en cuestión es posterior a esta fecha, cuando Polínico hubiera cumplido al menos los veinte años y hubiera sido inscrito en las listas de ciudadanos movilizables. Tisimenes, que comparece en la misma estela y en la línea 9, había sido, asimismo, vencedor en los Juegos Píticos. ${ }^{59}$ Si Polínico venció en la lucha juvenil en Olimpia en 448, tendría entonces entre 12 y 18 años, más bien entre 14 y 18. Si para la batalla de Delio en 424 se movilizaron los dos tercios de los efectivos tespieos, podemos suponer que se enviaron los adultos entre 20 y 39 años, por lo que Polínico tendría entre 38 y 42 años y estaría al borde del límite de la movilización, lo que nos daría una edad de 14 o 15 años en 448 y situaría la fecha de su nacimiento hacia 463-462. Esto excluye la batalla de Enófita, librada en 456, y hace difícil pensar también que se tratara de la batalla del Coronea, del año 446, si bien esta última fecha es también posible. Es decir, si Polínico fue olimpiónico en 448 con 18 años, hubiera tenido justo 20 años en 446 . No conocemos otras batallas donde el número de tespieos caídos pudieran pasar del centenar.

Ciertamente este polyandrion podría albergar a los muertos tespieos en la batalla de Delio, pero, con todo, subsisten muchas dudas. También procede de la necrópolis de Tespias una estela de mármol blanco, coronada por un frontón y hallada en 1889 en Makri Ekklisia, ${ }^{60}$ que menciona a los caídos de una misma familia en varias batallas diferentes:

\begin{tabular}{|c|c|}
\hline 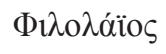 & ¿vac.? \\
\hline$\Phi \eta \gamma \eta ́ \alpha \varsigma$ & 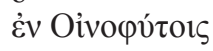 \\
\hline$\Lambda \alpha v \kappa \lambda \varepsilon \varsigma$ & $\dot{\varepsilon} v ' \Omega \rho \omega \pi$ о \\
\hline 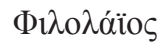 & $\dot{\varepsilon} v^{\prime} \Omega \rho \omega \pi \mathrm{o}$ \\
\hline 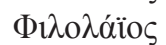 & 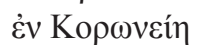 \\
\hline
\end{tabular}

El estilo de las letras data, como temprano, de mediados del siglo IV, por lo que pudo tratarse de una copia de una estela más antigua encargada por dicha familia. Dos miembros de esta familia, Laucles y Filolao, cayeron en Delio, que para los beocios fue librada en el territorio de Oropo. ${ }^{61}$ De ser así, al menos algunos de los muertos en Delio no fueron enterrados en el polyandrion, sino en su tumba familiar. La disposición de los nombres no deja de ser también inesperada ya que la batalla de

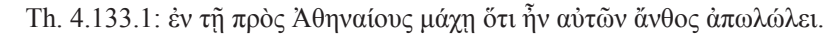

57 Th. 4.97.1.

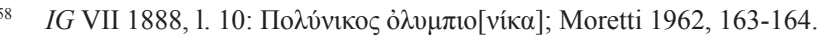

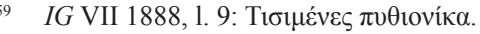

60 SEG 19.363; 53.471; IThesp $\mathrm{n}^{\circ}$ 488; Plassart 1958, 133-134, $\mathrm{n}^{\circ}$ 174, dimensiones 79 x 48 x $14 \mathrm{~cm}$. Cf. Schachter $2003,70, n^{\circ} 5$.

$61 \quad$ Th. 4.92.1.
} 
Oropo/Delio fue posterior a Coronea y, sin embargo, aparece en las líneas anteriores. Podría tratarse de un cenotafio, pero tampoco ninguno de los dos nombres de esta familia figura en las estelas conservadas del túmulo, o quizás de heridos que fallecen tiempo después de la batalla. En definitiva, la adscripción del túmulo a la batalla de Delio y al año 424, con ser verosímil, no deja de ser dudosa. Quizás podamos pensar, sobre la base del estilo de las letras, que estamos ante los caídos en dos batallas diferentes, una de las cuales pudo ser Delio. En todo caso, podemos considerar que se trata de una tumba del siglo $\mathrm{V}$, en torno a mediados o a la segunda mitad de esta centuria.

En el polyandrion de los tespieos varios de los cuerpos, que presentan numerosas heridas cortantes, fueron inhumados a un metro de profundidad y otros fueron cremados. Se ha pensado que los cadáveres inhumados, aun cuando pertenecieran a la misma batalla, fueron enterrados antes y otros, que habrían llegado más tarde, habrían recibido el rito de la cremación. Tal explicación parece demasiado compleja, y quizás debamos pensar simplemente en tradiciones familiares distintas. ${ }^{62}$ En todo caso, como veremos, ambos ritos de inhumación y de cremación coexisten en otros polyandria en Beocia, como en la fosa común de los tebanos muertos en la batalla de Queronea, aunque predomina siempre la inhumación.

En el túmulo tespieo y sobre la pira se depositaron numerosas ofrendas y, si el polyandrion data del siglo $\mathrm{V}$, se ha hallado en él también cerámica del siglo IV que podría explicarse como ofrendas posteriores, colocadas en años y décadas sucesivas, en recuerdo de unos muertos heroizados. En Atenas, Platón describe la costumbre anual de realizar ritos en honor de los héroes muertos. ${ }^{63}$ Conocemos, además, la existencia de una carrera con armas que partía del demosion $\operatorname{sem}^{64} \mathrm{y}$, asimismo, una carrera de antorchas, ${ }^{65}$ un desfile ${ }^{66}$ y diversas actividades ecuestres.${ }^{67}$ Es posible que Tespias tuviera también una forma parecida de honrar a sus muertos en combate, incluso con unos juegos funerarios, lo que indicaría que las ofrendas posteriores depositadas en el polyandrion no fueron solamente un asunto privado y familiar. Además del modelo homérico de los funerales de Patroclo, ${ }^{68}$ la existencia de juegos funerarios y conmemorativos de una batalla no era un fenómeno desconocido en Beocia. De hecho, por ejemplo, desde la victoria griega en Platea, en 479, se celebraban aquí cada cuatro años los Juegos Eleuterios, que tenían establecidos premios muy importantes, especialmente para la carrera. ${ }^{69}$

Se ha pensado también que, tanto el empleo del estilo en stoichedon en las nuevas inscripciones tespieas como la utilización de estelas con el nombre de los caídos, ${ }^{70}$ podrían revelar nuevamente una influencia ateniense y que quizás el memorial comprendiera también un epigrama, que no ha sobrevivido. La costumbre de erigir estelas con el nombre de los caídos en combate ya tenía precedentes en la propia

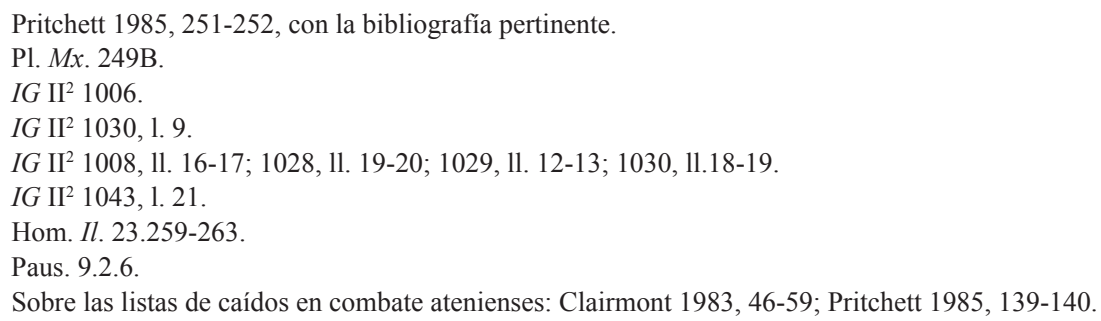


necrópolis tespiea, como hemos visto en el caso de la inscripción anterior. ${ }^{71}$ Con ser probable la influencia ateniense, es evidente que este polyandrion refleja otros ascendientes, especialmente la tumba en la que habían sido enterrados tiempo atrás los tespieos en las Termópilas y que estaba coronada por la estatua de un león. Ciertamente, a lo largo del siglo $\mathrm{V}$ el león se muestra como un símbolo del valor, pero, en el caso de los tespieos, el león del polyandrion conectaría a los que allí yacían con sus antepasados que habían perecido en las Termópilas, defendiendo a la Hélade contra los bárbaros.

\subsection{El polyandrion de los tespieos del siglo IV a.C.}

En 1920, Keramopoullos ${ }^{72}$ publicó dos fragmentos de una misma inscripción que fueron hallados en 1891 embutidos en la muralla de Kastro, esto es, en los muros de la antigua Tespias. Dicho epígrafe fue estudiado también por Wilhelm ${ }^{73}$ y por Plassart. ${ }^{74}$

Se trata de una estela de mármol local azulado, rota por todos sus lados, con una altura máxima de $43 \mathrm{~cm}$ y una longitud máxima de $28(0,43 ; 0,29 ; 0,145)$. Estaba coronada por un frontón del que se conserva el arranque de las líneas oblicuas que lo enmarcarían. La altura del frontón sería aproximadamente de unos $12 \mathrm{~cm}$ y la longitud total de la estela de un metro, por lo que conservamos aproximadamente la mitad de su longitud original $(0,54 \mathrm{~m})$. La primera línea ha sido restaurada como

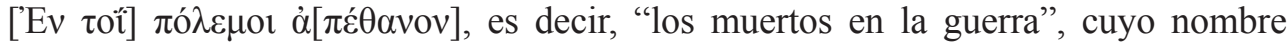
concreto no se menciona. Tras la primera línea, el texto se divide en dos columnas que recogen los nombres de los caídos en dicho conflicto. La columna izquierda (col. I) está escrita en alfabeto epicórico, mientras que la derecha (col. II) está grabada en alfabeto jónico-ático. Se conservan diez nombres en la columna derecha y el final de los nombres de otros tres en la izquierda. En esta última columna las letras tienen una altura de $3 \mathrm{~cm}$ en la línea 1 y entre 2 y 2,5 cm en las siguientes. En el caso de la columna derecha, las letras del primer nombre tienen una altura de $1,7 \mathrm{~cm}$ y el resto de 1,4 con un interlineado de $0,2 \mathrm{~cm} .{ }^{75} \mathrm{Su}$ localización original debía de estar en la necrópolis tespiea, en un polyandrion donde estarían enterrados los muertos listados en el epígrafe. La columna II pudo tener también más nombres de los conservados.

Aparentemente, el estilo de las letras se remontaría al siglo IV. Keramopoullos creyó que se debía atribuir a los años 355 a 346, en el contexto de la Tercera Guerra Sagrada, o a los tespieos que fueron con Alejandro a Asia, ${ }^{76}$ mientras que Wilhelm pensó en la Guerra de Corinto. ${ }^{77}$ Plassart volvió a estudiarla pero no la fechó. ${ }^{78}$ Sin embargo, el estilo de las letras de las contribuciones en la Tercera Guerra Sagrada y la dedicatoria colectiva a Zeus Soter de los jinetes beocios que acompañaron a

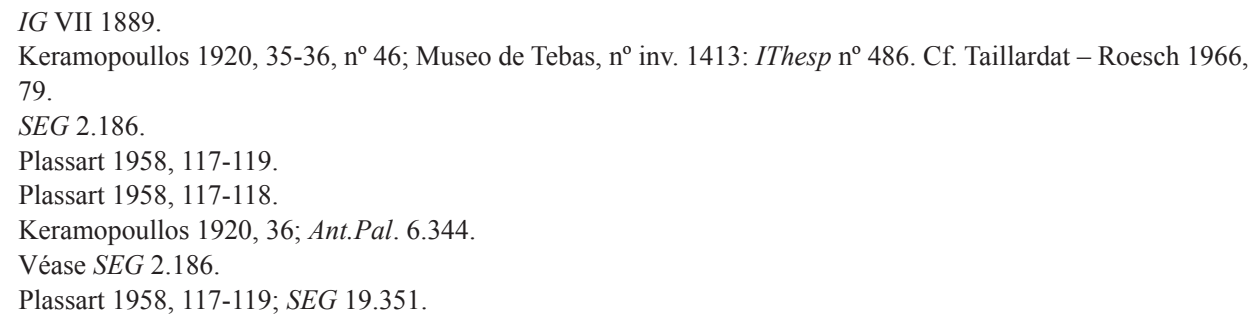


Alejandro a $\mathrm{Asia}^{79}$ no muestran similitudes con la estela tespiea y, aparentemente, es anterior a ambas. Tras la batalla de Delio, los beocios participaron en la batalla de Mantinea con cinco mil hoplitas y quinientos jinetes y, entre Delio y la batalla de Leuctra ${ }^{80}$ sólo la Guerra de Corinto podría ser considera polemos, por lo que los caídos procederían quizá de este conflicto. Sobre esta base se ha pensado que los nombres podrían hacer referencia a los muertos en dos teatros de operaciones distintos o en dos enfrentamientos en un mismo conflicto. En consecuencia, la columna izquierda correspondería a la batalla de Haliarto del año 395, mientras que la columna derecha recogería los muertos en Nemea en el año siguiente. ${ }^{81}$ Sin embargo, tal hipótesis supone considerar que se habría preparado una estela en 395 para recoger también a aquellos que habrían de perecer más adelante, algo no fácil de explicar. Quizá sea más plausible pensar que estamos ante la obra de dos lapicidas o talleres distintos, un fenómeno habitual, que recogen los nombres de los caídos en una misma batalla, posterior obviamente al 403/2, fecha en la que se adopta en Atenas el alfabeto jónico. Aunque ciertamente posible, el año 395 parece quizás demasiado temprano para la introducción del alfabeto jónico en Beocia. Asimismo, los nombres recogidos en la estela podrían derivar de otros enfrentamientos posteriores, que pueden ser considerado notables, por ejemplo, en 378/7, cuando los tespieos, bajo el mando del harmosta espartano Fébidas, fueron derrotados por los tebanos y, de acuerdo con Jenofonte, no muchos fueron muertos, lo que se correspondería bien con el número de los listados en la estela. ${ }^{82}$

En definitiva, en mi opinión, este polyandrion habría sido erigido posiblemente entre la batalla de Mantinea (385) y la batalla de Leuctra (371), probablemente en el primer cuarto del siglo IV. La Guerra de Corinto, si bien no completamente descartable, parece una fecha demasiado temprana y la de Tercera Guerra Sagrada demasiado tardía. En todo caso, la adopción del alfabeto jónico revela una, a mi juicio, indudable influencia ateniense, para la que el período de la recreación de la Confederación beocia, a partir del año $378,{ }^{83}$ y el establecimiento de la Segunda Liga Ateniense (febrero del 377$)^{84}$ aportan un buen contexto.

\subsection{El polyandrion del siglo III a.C.}

En 1936, Keramopoullos dio a conocer una inscripción que recogía una lista de tespieos caídos en una batalla, cuyo nombre no se mencionaba. ${ }^{85}$ Este autor publicó sólo las líneas 11-18 del texto, que corresponde a la esquina inferior izquierda de una estela con frontón, hecha en piedra caliza beige con vetas rosáceas, encontrada en 1889 en las ruinas de Makri Ekklisia, al este de Tespias. Dicha estela se halló en ocho fragmentos con unas dimensiones de 0,90 (bajo el frontón) x 0,57 x 0,21 m. Las letras y el espaciado de línea miden $0,016 \mathrm{~m}$.

\footnotetext{
IG VII 2420 (contribuciones en la Tercera Guerra Sagrada). IG VII 3206 (ca. 329, expedición en Asia).

80 Los tespieos no participaron en Leuctra (cf. Paus. 9.13.8). Sobre el estilo de las letras en 371, véase el epigrama que conmemora dicha batalla, $I G$ VII 2462.

81 Taillardat - Roesch 1966; Roesch - Darmezin 1983, 136. Haliarto: X. HG 3.5.17-19; Diod. 14.81.1-3; Paus. 3.5.3-5. Nemea: X. HG 4.2.20; Diod. 14.83.2.

82 X. $H G$ 5.4.42-45. Clairmont 1983, 236-237; Pritchett 1985, 141-143.

83 Pascual 1992.

$84 I G \mathrm{II}^{2} 43$, con los tebanos como aliados (1. 79).

85 Keramopoullos 1936, 26, no 194; Museo de Tebas, $\mathrm{n}^{\circ}$ inv. 2114; IThesp $\mathrm{n}^{\circ} 487$.
} 
Lamentablemente sólo dos fragmentos de los ocho originales parecen conservarse en el museo: la parte inferior izquierda con las líneas 10 a 18 y un fragmento no inventariado con las líneas 1 a $6 .{ }^{86} \mathrm{El}$ texto es de difícil lectura en algunas líneas, especialmente 2, 4 y 8 , pero indudablemente se refiere a los muertos en combate tal y como figura en la línea $1(\Theta \varepsilon ı \sigma \pi \varepsilon \dot{\varepsilon} \varepsilon \zeta)$ y debe provenir de un polyandrion que se elevó en la necrópolis de Tespias. La inscripción fue encontrada en el mismo lugar que las estelas $I G$ VII 1888 de los muertos en el siglo V. Sin embargo, por el estilo de las letras, la estela recogería los caídos en algún momento del siglo III, quizás en la segunda mitad. La batalla de Queronea, librada en el año 245, en la que los beocios sufrieron una aplastante derrota a manos de los etolios, resulta una fecha obvia ${ }^{87}$

Como vemos, los tespieos siguieron conservando la costumbre de enterrar en una tumba colectiva en la necrópolis de la ciudad a los caídos en combate. Asimismo, la proximidad de esta lista a las estelas del polyandrion del siglo $\mathrm{V}$ apuntaría precisamente a la existencia en esta zona de la necrópolis tespiea de un demosion sema, donde, como en Atenas, se recordaría a lo largo de más de dos siglos mediante tumbas y estelas colectivas a los que murieron por la polis.

\section{El polyandrion de los tanagreos}

En el Museo de Tanagra (ver Fig. 1) se conserva una inscripción con una lista de caídos en combate que procede de la necrópolis de la ciudad antigua ${ }^{88}$ Realizada en mármol negro local, se trata de una estela casi cuadrangular que mide $0,834 \times 0,814 \times$

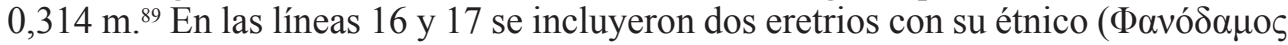

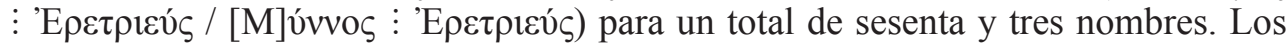
nombres de los eretrios fueron grabados por una mano distinta del resto de nombres.

Es evidente que el epígrafe se disponía en un polyandrion en el que yacían sesenta y un ciudadanos tanagreos y dos de la vecina ciudad de Eretria, situada en la isla de Eubea, justo enfrente de la costa tanagrea. Estos eretrios pudieron ser metecos que fueron movilizados con el contingente tanagreo o quizás exiliados por sus tendencias oligarquizantes y antiatenienses. Dittenberger pensó que la estela listaba a los caídos en 426 en un enfrentamiento con los atenienses, ${ }^{90}$ pero Keramopoullos vinculó la inscripción con la batalla de Delio, donde los tanagreos pudieron sufrir también bastantes pérdidas..$^{91}$ No es posible saberlo y no hay vestigios de otras estelas que recogieran más nombres. ${ }^{92}$

Uno de los ciudadanos tanagreos recogidos en la estela es Saugenes (línea 53), que ha sido vinculado con la famosa estela de Saugenes del Museo de Tebas, ${ }^{93}$ de manera que se ha pensado que habría sido sepultado junto a sus compañeros en este polyandrion pero que, al mismo tiempo, su familia le habría dedicado un estela individual en el lugar de enterramiento de su estirpe con una imagen heroizada

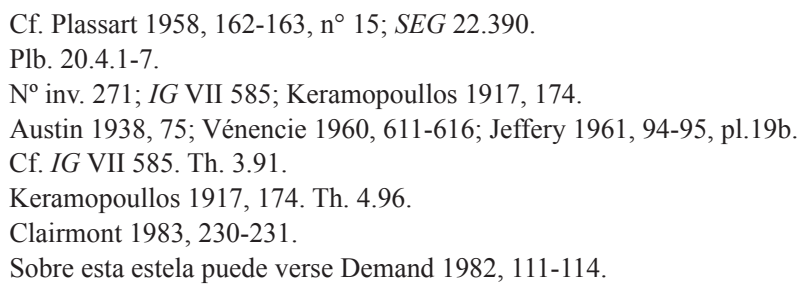


como cenotafio. ${ }^{94}$ Tal hipótesis es indemostrable y parece demasiado compleja, pero, con todo, la lista de muertos en combate probaría que la costumbre de elevar un polyandrion colectivo en la necrópolis de la ciudad, sobre la que se disponían estelas con los nombres de los que habían perecido en combate, estaba bien arraigada ya en el siglo $\mathrm{V}$ en todas las ciudades beocias y no sólo en Tespias. ${ }^{95}$

\section{Los polyandria en Tebas}

\subsection{El polyandrion de los tebanos caídos en la conquista de Tebas por Alejandro}

Cuando se aproximaba a Tebas y antes de entrar en la ciudad, Pausanias afirma que "hay un polyandrion no lejos de las puertas, donde yacen todos los que murieron luchando contra Alejandro y los macedonios". ${ }^{96}$ Asimismo, no lejos de este polyandrion se encontraba, según nuestro autor, el lugar donde los tebanos aseguraban que Cadmo sembró los dientes del dragón al que dio muerte junto a la fuente que allí también brotaba, dientes de los que la tierra hizo nacer hombres, los llamados Espartos. Justo a la derecha de las puertas que se alzaban en este sitio, se elevaba una colina consagrada a Apolo. Tanto la colina como el dios se llamaban Ismenio, pues aledaño a este lugar corría también el río Ismenio (Fig. 4). ${ }^{97}$

Pausanias se dirigía a Tebas viniendo desde Platea, por lo que observaba la ciudad desde el sur y hacia el norte y, efectivamente, a la derecha de su vista quedaba la colina del Ismenio, que se eleva al sureste de la Cadmea. Sobre la colina, el hallazgo de inscripciones y las excavaciones han podido identificar el santuario de Apolo Ismenio. ${ }^{98}$ Las Puertas que, de acuerdo con Pausanias, estaban "no lejos" del polyandrion son las Electras, que se abrían precisamente en la parte suroriental del muro de la Cadmea. ${ }^{99}$ El río Ismenio era indudablemente el actual Agianni, el arroyo que corre entre la Cadmea y la colina del Ismenio. ${ }^{100} \mathrm{El}$ lugar donde el mito tebano situaba la muerte del dragón por parte de Cadmo y la siembra de los dientes de los que nacieron los Espartos debía de situarse entre el polyandrion mencionado y la fuente de Ares, hoy en día Pege (la fuente), que brota en las proximidades del Ismenio. ${ }^{101}$

Además de ser una zona especialmente sagrada para los tebanos, toda el área al sur de la Cadmea poseía también una evidente connotación funeraria. Aquí se

\footnotetext{
Clairmont 1983, 231.

Sobre las listas de caídos en combate en Atenas a partir del siglo V: Arrington 2011.

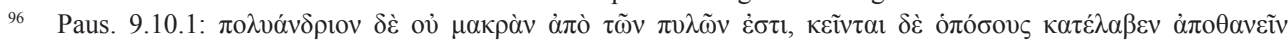

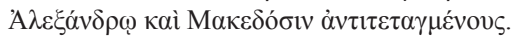

97 Paus. 9.10.1-2.

98 Ismenio quizá fuera una vieja divinidad que sobrevivió bajo la advocación a Apolo, como los casos de Heracles Cárope y el propio Apolo Ptoio (cf. Schachter 1967; 1981, 78-85).

99 Keramopoullos 1917, 7-32, figs. 3, 4-18.

100 Gomme 1911/12, 209-210; Symeonoglou 1985, 8. Sobre los tres ríos de la antigua Tebas, Dirce, Estrofia e Ismenio, las fuentes de Ismenio o Pie de Cadmo, de Edipo y de Ares, puede verse: Pi. I. 6.74, 8.20; O. 10.85; Paus. 9.10.2-5, 18.6, 24.3; Str. 9.2.24; Ael. VH 12.57; A. Th. 377-379; E. Ph. 818, 1120-1154; Demand 1982, 7; Symeonoglou 1985, 5, 8-10.

101 Apollod. 3.4.1-2; Schol. A.R. 3.1179-1180; Schol. Hom. Il. 2.494; Bursian 1862, 226; Keramopoullos 1917, 320-321.
} 
extendía la necrópolis más importante de la ciudad, en la actual Kolonaki, y, según Píndaro, junto al ágora de Heracles se ubicaba aquí la tumba de Anfitrión. ${ }^{102}$ Asimismo, la fuente de Ares, donde Cadmo dio muerte al dragón, y la tumba de Caanto estaban próximas. Caanto sucumbió por obra de Apolo, cuando trataba de evitar que el dios raptara a su hermana Melia. ${ }^{103}$

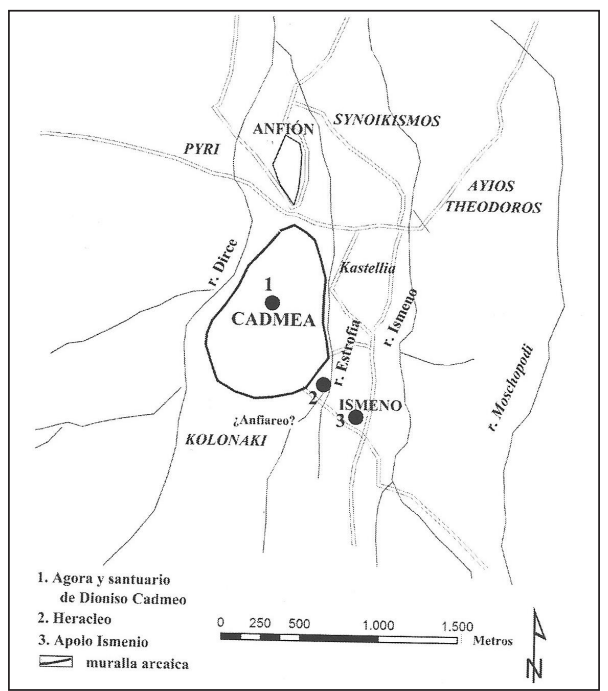

Fig. 4. La ciudad de Tebas (J. Pascual).

La disposición de la necrópolis y de diversos monumentos funerarios en la zona hacían especialmente oportuno que el polyandrion se elevara aquí, pero además precisamente la batalla principal librada entre tebanos y macedonios en 335 tuvo

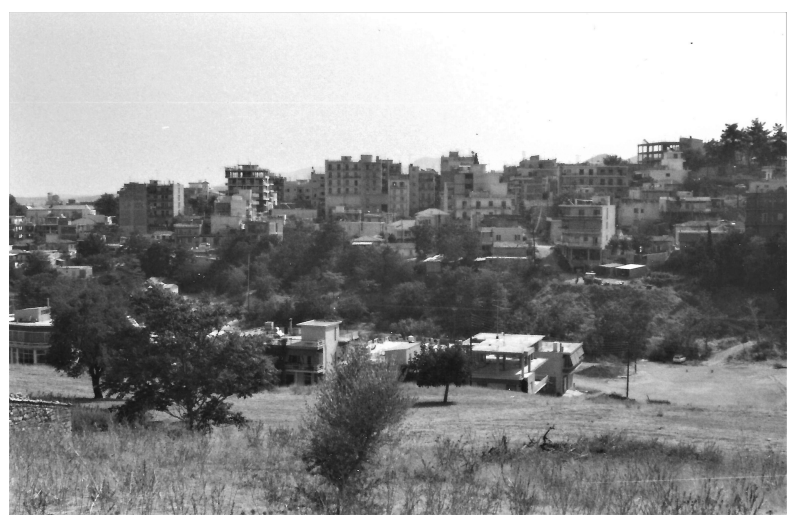

Fig. 5. La Cadmea desde el Ismenio con el valle en el que tuvo lugar la batalla final (J. Pascual). 
lugar entre las Puertas Electras y la colina del Ismenio como indican Plutarco, Diodoro y Arriano (Fig. 5). ${ }^{104}$ Cabe suponer, como veremos, que los tebanos fueron enterrados muy próximos al lugar en que cayeron.

Plutarco afirma que la ciudad fue tomada, saqueada y arrasada, y que sólo fueron respetados los descendientes de Píndaro, los proxenos de los macedonios, los sacerdotes y aquellos que habían votado contra la deserción. Indica, además, que los muertos alcanzaron la cifra de seis mil y que unos treinta mil más fueron esclavizados. ${ }^{105}$ Diodoro dice que la ciudad fue saqueada y su población masacrada y que más de seis mil tebanos fueron muertos y otros treinta mil fueron apresados; después de todo ello, Alejandro enterró a los macedonios muertos, que eran más de quinientos, y sometió el destino de la ciudad a la decisión del Consejo de los aliados, que votó que ésta fuera arrasada, los prisioneros vendidos como esclavos -lo que reportó cuatrocientos cuarenta talentos de plata- y que los exiliados tebanos fueran proscritos de toda Grecia. ${ }^{106}$ Arriano, por su parte, asegura que los macedonios, focidios, plateos y el resto de los beocios dieron muerte a los tebanos dentro de la ciudad, sin perdonar siquiera a mujeres y niños, y que Tebas fue arrasada hasta los cimientos, su territorio distribuido entre los aliados, y se esclavizó a todos los niños, mujeres y hombres supervivientes, excepto a los sacerdotes y sacerdotisas y a los que se habían mantenido fieles a Alejandro o habían sido proxenos de los macedonios. ${ }^{107}$ Es decir, tras la toma de la ciudad, los macedonios enterraron a sus muertos inmediatamente y podemos suponer que los pocos supervivientes tebanos que fueron dejados libres, los sacerdotes y los promacedonios, hicieron lo propio con los tebanos caídos, sepultándolos en una fosa común, cerca del lugar en que cayeron. Quizá, cuando la ciudad fue reconstruida en 316, el recinto se acotó y se acondicionó con un túmulo.

Fuera de la Cadmea, justo al sudeste de la ciudad antigua, Keramopoullos trató de encontrar este polyandrion y halló en esta área restos clásicos y debajo de ellos cerámica del Heládico Reciente. ${ }^{108}$ También descubrió un muro isodómico de más de un metro de largo y 1,45 m de ancho. Excavó el muro a lo largo de $15 \mathrm{~m}$ y lo describió con una altura de $2 \mathrm{~m}$. Keramopoullos consideró que se trataba del muro clásico que iba hacia Agios Loukas. Los datos derivados de esta excavación no permiten relacionarlos con certeza con el polyandrion de los tebanos muertos en 335 , pero es indudable que un túmulo colectivo existió en esta zona de la ciudad.

\subsection{IG VII 2427: otro polyandrion en la necrópolis tebana}

Keramopoullos publicó a principios del siglo XX una inscripción que se hallaba en estado fragmentario. ${ }^{109}$ Dicha inscripción conservaba veintiocho líneas y contenía una lista de nombres de ciudadanos tebanos caídos en combate. Se halló en la necrópolis de Kolonaki, el cementerio que, como hemos visto, se extendía al sur de la ciudad donde se localizaba también el polyandrion de los que fueron muertos por Alejandro, y pensó que la lista tenía que ver con ellos.

\footnotetext{
104 Plu. Alex. 11.8-12 [Diod. 17.11-12]. Arr. Anab. 1.7-9.

105 Plu. Alex. 11.10-12.

106 Diod. 17.13.1-6, 14.1-4.

107 Arr. Anab. 1.8.8, 9.6, 9.9.

108 Keramopoullos 1917, 314-315.

109 Keramopoullos 1917, 314, n. 2.
} 
A diferencia de otras estelas, los nombres no fueron inscritos en líneas separadas y de cada uno de ellos se anota su nombre y el adjetivo patronímico. El alfabeto empleado es una mezcla de beocio epicórico y jónico-ático. Dittenberger pensó que la estela podía datarse hacia mediados del siglo IV, en torno a $350 .{ }^{110}$ Puede tener una datación más temprana, en la primera parte del siglo, a lo que apuntaría la combinación de alfabetos. No faltan desde luego conflictos y expediciones en la primera parte del siglo IV a las que asignarles los caídos mencionados en esta estela, ya sea en el Peloponeso, el norte de Grecia o la propia Beocia. Podemos pensar, incluso, en un contexto de la Tercera Guerra Sagrada, pero lo que interesa aquí reflejar es que el epígrafe es anterior al polyandrion de los muertos durante la conquista de la ciudad por Alejandro y que, por lo tanto, existiría al menos otro polyandrion en la necrópolis tebana. De este modo, la costumbre de enterrar a los caídos en batalla en un túmulo colectivo parece haber sido habitual en todas las ciudades beocias, como el caso tebano que estamos contemplando, e incluso podríamos pensar, teniendo en cuenta la proximidad del túmulo de 335 , situado en la misma necrópolis meridional de la ciudad, que se habría definido también aquí un demosion sema tebano.

\section{Un posible polyandrion plateo}

En 1925, el Bulletin du Correspondance Hellénique anota, en una breve noticia, la entrada en el Museo de Tebas de una inscripción procedente de Platea y que permanece sin publicar: "Béotie - Thebes. Le musée a reçu un certain nombre de stèles funéraires: l'une, qui provient de Platées, contient un catalogue de soldats morts à Olynthe". ${ }^{111}$ Con esta escasa noticia no es fácil interpretar la inscripción. Cabría preguntarse, en primer lugar, sobre la campaña en Olinto en la que hubieran participado estos plateos que habrían hallado la muerte combatiendo en la lejana Calcídica. Evidentemente quedan descartados, en principio, los años 427 a 386 y 373 a 338 , en los que la ciudad fue arrasada y despoblada por los tebanos. Un período bastante obvio puede ser el de las campañas que los lacedemonios y sus aliados emprendieron contra Olinto entre los años 383 y $379 .{ }^{112}$ En este período posterior a la Paz del Rey, la confederación beocia había sido disuelta, Platea había sido restaurada con ayuda de los lacedemonios y la ciudad se había convertido en aliada de los espartanos, una alianza que se mantenía todavía a principios de los años setenta del siglo IV, cuando los plateos aceptaron una guarnición lacedemonia para defenderse precisamente de los tebanos. ${ }^{113}$ No sería de extrañar, en consecuencia, que los plateos hubieran contribuido, en la medida de sus modestas fuerzas, a las expediciones lacedemonias contra Olinto junto a otras ciudades beocias, y que algunos de sus ciudadanos hubieran caído en los combates que se desarrollaron en torno a la ciudad. Después de morir en Olinto y en un largo trayecto por vía terrestre, los caídos habrían sido llevados a Platea y, en lo que nos interesa aquí, de la estela se infiere que fueron enterrados todos juntos en un polyandrion, que se debió de alzar en la necrópolis de Platea con una inscripción que mencionaba sus nombres y el lugar en el que cayeron.

\footnotetext{
Cf. $I G$ VII 2427.

BCH 49, 1925, 456.

X. $H G$ 5.2.11-27, 5.2.37-42, 5.3.1.9, 5.3.1.18-20, 5.3.1.26; Diod. 15.19.3-4, 15.20.3, 15.21-23.

113 Plu. Pel. 15.6, 25.8.
} 


\section{El polyandrion de los caídos en la batalla de Queronea (338 a.C.)}

Cerca de la ciudad de Queronea, en el oeste de Beocia y sobre la llanura, se dispone un enterramiento colectivo, rodeado por un recinto de piedra y rematado por un león, que corresponde casi con toda seguridad a los tebanos que perecieron en combate en la batalla de Queronea, concretamente a los componentes del Batallón Sagrado, el cuerpo de elite de la ciudad (Fig. 6). ${ }^{114}$

La identificación de la fosa común de los tebanos es segura a partir del relato de Pausanias quien, en el camino que va de Lebadea a Queronea, vio el polyandrion que denomina "de los tebanos que murieron en la lucha contra Filipo". ${ }^{115}$ El Periegeta continúa diciendo que dicha tumba no tiene ninguna inscripción porque la fortuna no les acompañó de acuerdo con su coraje, pero que se halla coronada por un león, que para nuestro autor reflejaba el valor de muchos hombres.

De acuerdo con Plutarco, durante la batalla, Alejandro fue el primero en lanzarse contra el Batallón Sagrado de los tebanos, que fue aniquilado. ${ }^{116}$ Después de la lucha, Filipo reconoció el campo de batalla y se detuvo donde habían caído los trescientos con sus armaduras, alcanzados todos ellos de frente por las sarisas. ${ }^{117}$ Finalmente, Justino indica que Filipo vendió a los tebanos los prisioneros de guerra y también el terreno para sepultar a sus muertos. ${ }^{118}$

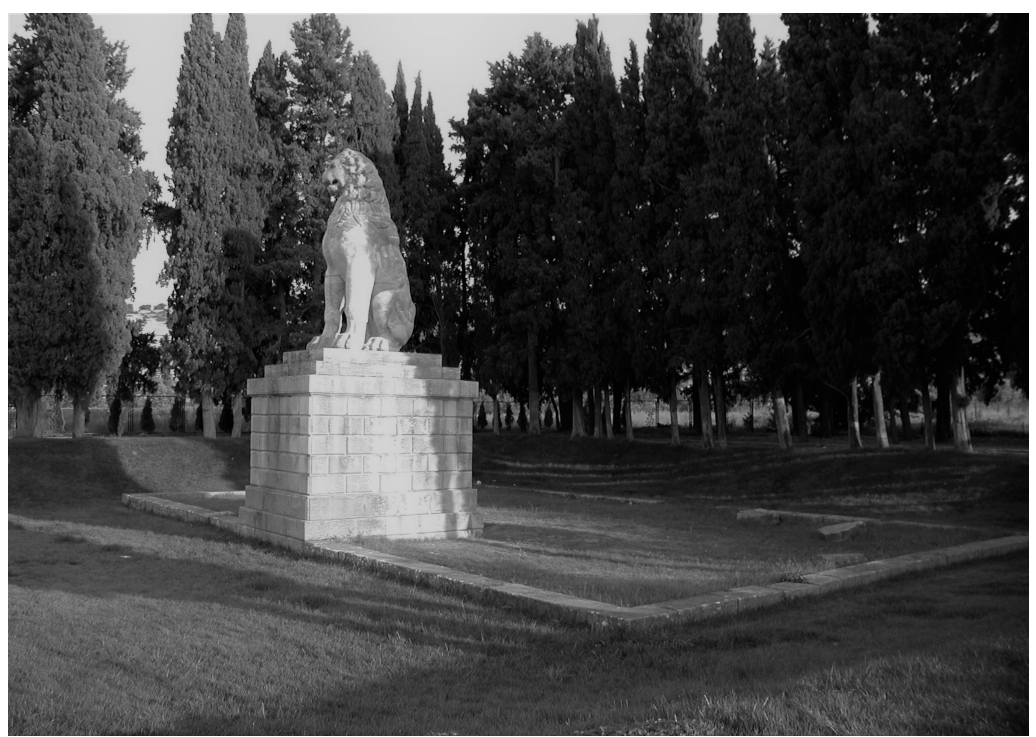

Fig. 6. La fosa común de los tebanos en Queronea (J. Pascual).

114 Sobre el Batallón Sagrado tebano, formado por 150 parejas de amantes, véase Dinarco 1.72-73, 2; Plu. Pel. 18-19, 23; Alex. 9.2; Polyaen. 2.5.1; Dio Chr. Or. 22.2; Max. Tyr. 18.2; Ath. 13.561-562; 602a; Leitao 2002; Georgiadou 2006.

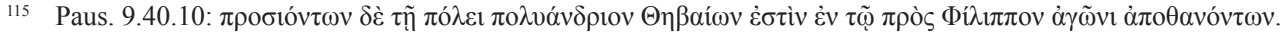

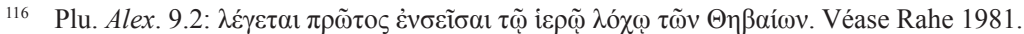

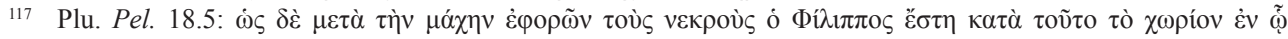

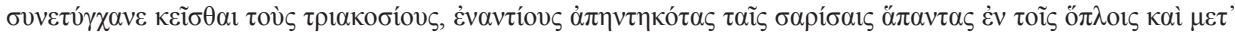
$\dot{\alpha} \lambda \lambda \hat{\eta} \lambda \omega v \dot{\alpha} v \alpha \mu \varepsilon \mu 1 \gamma \mu \varepsilon \dot{v}$ ovৎ.

118 Just. 9.4.6. 
El león que coronaba la tumba de los tebanos fue descubierto a principios del siglo XIX y la fosa común de los tebanos se excavó en 1879. Las excavaciones revelaron un recinto de 22,55 m de ancho y 13,45 m de largo, orientado N-NO / $\mathrm{S}-\mathrm{SE}$, que estaba rodeado por un muro perimetral construido en sillería isodómica y que quizá se elevara hasta una altura de 4,26 m. En el muro destacaba una gran plataforma de 3,65 $\mathrm{m}$ de ancho y $4,30 \mathrm{~m}$ de profundidad que se proyectaba en el interior del recinto entre 1,30 y 1,40 m. Dicha plataforma sirvió obviamente como pedestal sobre la que se alzaba la estatua del león.

Es posible que la tumba tuviera forma de túmulo, pues la altura del muro perimetral así lo sugiere. En este sentido, el estado de conservación del propio muro de peribolos, bastante bueno, revelado durante las excavaciones, apunta a que parte de él estuvo cubierto por la tierra y se usó, por lo tanto, de contrafuerte. Phytalis, uno de los primeros excavadores, consideró el monumento como un túmulo ascendente sobre un recinto cuadrangular, con el león que emergía en la parte frontal. En un área al oeste del león, de 4,55 por $6,30 \mathrm{~m}$, y a $45 \mathrm{~cm}$ de profundidad, se encontraron 254 esqueletos dispuestos en siete filas. Además, en la segunda fila, entre los esqueletos números 13 y 14, se exhumaron un conjunto de huesos y cenizas que indica la cremación de uno o varios hombres. Es decir, se utilizaron ambos ritos, inhumación y cremación, si bien esta última fue minoritaria. ${ }^{119}$

Entre los esqueletos se hallaron cinco puntas que pueden ser más de jabalina que de lanza y que se conservaban entre los cuerpos, por lo que o bien fueron dejadas en la tumba o bien estaban incrustadas en los mismos. Los esqueletos encontrados en la fosa presentan numerosos traumatismos peri mortem, así como cuantiosas evidencias de cortes en la parte baja de las piernas que reflejan un combate a corta distancia con armas cortantes. Los hallazgos materiales son modestos y se reducen a unas cuantas cerámicas, la mayor parte sin decoración, fragmentos de armas, como dagas, espadas, puntas de lanza, y muchos estrígiles sencillos de hierro. Es posible pensar que la tumba contenía casi un estrígil para cada persona, un objeto conectado con la vida cotidiana pero, además, símbolo de libertad y vinculado estrechamente a la cultura tebana y beocia en general, que gustaba de la frecuentación del gimnasio y de la práctica atlética. ${ }^{120}$

La monumentalización de la tumba y la estatua del león debieron de llevarse a cabo tiempo después de la batalla, quizás después de 316 , una vez que Casandro restaurara Tebas, o incluso a principios del siglo III, cuando la ciudad era miembro de pleno derecho de la Confederación Beocia. ${ }^{121}$ De este modo, poco después de la batalla, los cuerpos de los hoplitas tebanos del Batallón Sagrado pudieron ser enterrados en una sencilla fosa común, de forma apretujada e improvisada, y con pocas ofrendas. En algún momento posterior se depositarían los restos de una cremación. Posiblemente se trataba de heridos en combate que fallecieron después de la inhumación. Treinta o cuarenta años más tarde esta fosa recibiría un recinto monumental con la escultura colosal del león, que se proyectaba también en el interior del recinto, si bien se puso un especial cuidado en no perturbar el enterramiento anterior.

119 Stamatakis 1880, 22-26; 1881, 16-20; Phytalis 1880, 347-352 (plano entre las páginas 398-399); Ma 2008, 7585 , con las referencias correspondientes.

120 Véase, por ejemplo, Nepos Epam. 5.2.

121 Ma 2008, 83-84. 


\section{Conclusiones}

En definitiva, la piadosa costumbre griega de enterrar a los muertos debía atenderse de manera especial en el caso de los caídos en combate por múltiples razones, ya que las circunstancias de su muerte los diferenciaban del resto: porque habían caído lejos de sus familiares y parientes, aquellos que estaban encargados expresamente de ofrecerles el ritual debido; porque habían perecido en tierra extranjera, fuera ésta amiga o enemiga; porque su cuerpo, sin la protección de los parientes, podía ser profanado por los enemigos o devorado por las bestias salvajes, visiones ambas que espantaban a los griegos; y porque habían perecido combatiendo en defensa de la patris, de la comunidad ciudadana. Los griegos fueron plenamente conscientes de la importancia que tenía honrar a aquellos que habían protegido a la comunidad aun a costa de su propia vida. Modelaron los honores que se les debían a través de la costumbre y de las epopeyas que se encontraban tan arraigadas en sus vidas y en su imaginación, tradiciones y relatos que fueron usados para venerar a los nuevos héroes que habían dado su vida por la polis. Es así que, sobre la costumbre y la épica, se superpuso la nueva ideología del hoplitismo y se llegó a definir un determinado ritual que incidía en el carácter heroico de los caídos. Además de todo ello -la tradición ancestral, la épica y el hoplitismo-, cabe reseñar también en el caso beocio una posible influencia ateniense.

Los espartanos preferían enterrar a los muertos en combate en el campo de batalla o en las proximidades del mismo. ${ }^{122}$ En Beocia, este enterramiento sobre el campo de batalla parece haber sido excepcional y sólo tuvo lugar bajo determinadas circunstancias, por ejemplo, en una derrota que habría impedido el traslado de los cuerpos. En los enterramientos en el campo de batalla nunca parecen haberse dispuesto estelas con los nombres de los caídos, cosa que sí sucedía cuando eran sepultados en la patria. Asimismo, los atenienses escogían incinerar a sus muertos. En el caso beocio la incineración parece haber sido una práctica muy minoritaria frente al predominio aparentemente abrumador de la inhumación.

Los beocios optaron por dar sepultura a los muertos en combate en la necrópolis de la ciudad, lo que implicaba un complejo ritual. Esto es, suponía unos mínimos cuidados de los cuerpos de los caídos en el campo de batalla, el posterior desplazamiento de los cadáveres, desde sitios tan alejados a veces como Olinto, y un proceso también probablemente muy elaborado ya en la patria. Aunque existieran sepulcros familiares que pudieran acogerles, una costumbre bastante habitual fue la construcción de una tumba colectiva en forma de túmulo, lo que permitiría definir una o varias áreas dentro de la necrópolis que pueden ser insertas en la tradición del demosion sema.

Salvo el epigrama de las Termópilas, que pudo obedecer a elementos excepcionales como el hecho de que yacieran junto a otros griegos que disponían de su propio epigrama, los beocios no parecen haber inscrito ningún epigrama sobre los polyandria y prefirieron siempre las estelas que recogieran los nombres de aquellos que habían fenecido en combate. Finalmente, desde las Termópilas al menos y previsiblemente como reflejo del polyandrion de los griegos en el Paso, se introdujeron las estatuas de leones como símbolo del valor, ya sea individual o colectivo.

Se configuró así en el mundo beocio un rico ritual que aunaba múltiples elementos e influencias y que tuvo como finalidad recordar y honrar principalmente en tumbas colectivas a un tipo especial de fallecidos, a aquellos ciudadanos -e incluso a los

Krentz 2007, 175. 
extranjeros-, a aquellos héroes, que habían sacrificado su vida en defensa de la comunidad.

\section{Referencias bibliográficas}

Arrington, N. T.

(2010a): Between Victory and Defeat: Framing the Fallen Warrior in Fifth-Century Athenian Art, PhD. diss., University of California, Berkeley.

(2010b): "Topographic Semantics: The Location of the Athenian Public Cemetery and Its Significance for the Nascent Democracy", Hesperia 79/4, 499-539 (https://doi. org/10.2972/hesp.79.4.499).

(2011): "Inscribing Defeat: The Commemorative Dynamics of the Athenian Casualty Lists", California Studies in Classical Antiquity 30/2, 179-212 (https://doi.org/10.1525/ ca.2011.30.2.179).

Austin, P. (1938): The Stoichedon Style in Greek Inscriptions, Oxford.

Bendlin, A. (2007): "Purity and Pollution", [en] Ogden (ed.), 2007, 178-189 (https://doi. org/10.1002/9780470996911.ch12).

Bowie, E. L.

(1997): “The Theognidea: A Step Towards a Collection of Fragments?”, [en] G. W. Most (ed.), Collecting Fragments. Fragmente sammeln (=Aporemata: Kritische Studien zur Philologiegeschichte 1), Göttingen, 53-66.

(2009): "Wandering Poets, Archaic Style", [en] R. Hunter-I. Rutherford (eds.), Wandering Poets in Ancient Greek Culture. Travel, Locality and Pan-Hellenism, Cambridge, 105135 (https://doi.org/10.1017/cbo9780511576133).

Bradeen, D. W. (1964): “Athenian Casualty Lists", Hesperia 33/1, 16-62 (http://dx.doi. org/10.2307/147027).

Bremmer, J. N. (2006): La religión griega. Dioses y hombres: santuarios, rituales y mitos, Córdoba.

Bruit Zaidman, L. - Schmitt-Pantel, P. (2002): La religión griega en la polis en época clásica, Madrid.

Burkert, W. (2007): Religión griega arcaica y clásica, Madrid.

Bursian, C. (1862): Geographie von Griechenland, vol. I, Leipzig.

Clairmont, C. (1983): Patrios Nomos. Public Burial in Athens during the Fifth and Fourth Centuries B.C.: The archaeological, epigraphic-literary, and historical evidence (=BAR International Series 161), Oxford.

Deacy, S. (2007): “Famous Athens, Divine Polis: The Religious System at Athens", [en] Ogden (ed.), 2007, 219-235 (https://doi.org/10.1002/9780470996911.ch15).

Demand, N. H. (1982): Thebes in the Fifth Century. Heracles Resurgent, London-BostonHenley.

Frazer, P. M. - Ronne, T. (1958): Boeotian and West Greek Tombstones, Lund.

Georgiadou, A. (2006): "The Wanderings of the Sacred Band: Uses and Abuses of an Erotic Tradition", Millenium 3, 125-141(https://doi.org/10.1515/9783110186437.125).

Gomme, A. W. (1911/12): "The topography of Boeotia and the theories of M. Berard", Annual of the British School at Athens 18, 189-210 (http://dx.doi.org/10.1017/ S0068245400008832).

Hanson, V. D. (1999): "Hoplite Obliteration: The Case of the Town of Thespiai", [en] J. Carman - A. Harding (eds.), Ancient Warfare. Archaeological Perspectives, Stroud, 203217. 
Hedrick, C. W. (2007): "Religion and Society in Classical Greece”, [en] Ogden (ed.), 2007, 283-296 (https://doi.org/10.1002/9780470996911.ch19).

Hiller, F. F. (1926): Historische Griechische Epigramme, Bonn.

Jeffery, L. H. (1961): The Local Scripts of Archaic Greece, Oxford.

Keramopoullos, A. D.

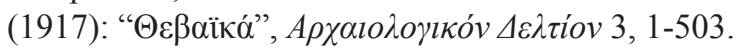

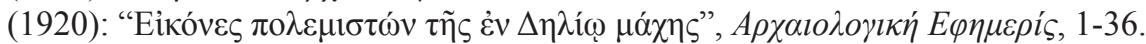

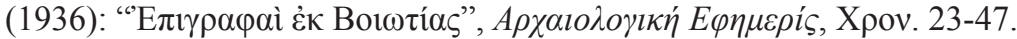

Krentz, P. (2007): "War", [en] P. Sabin - H. van Wees - M. Whitby (eds.), The Cambridge History of Greek and Roman Warfare. Volume I. Greece, the Hellenistic world and the rise of Rome, Cambridge, 147-185 (https://doi.org/10.1017/CHOL9780521782739.007).

Kurtz, D. C. - Boardman, J. (1971): Greek Burial Customs, London.

Leitao, D. (2002): "The Legend of the Sacred Band", [en] M. C. Nussbaum - J. Sihvola (eds.), The Sleep of Reason: Erotic Experience and Sexual Ethics in Ancient Greece and Rome, Chicago, 143-169.

Ma, J. (2008): "Chaironeia 338: Topographies of Commemoration", Journal of Hellenic Studies 128, 72-91 (http://dx.doi.org/10.1017/S0075426900000069).

Moretti, L. (1962): Ricerche sulle Leghe Greche. Peloponnesiaca-beotica-licia (=L'Erma di Bretschneider. Problemi e ricerche di storia antica 2), Roma.

Ogden, D. (ed.), (2007): A Companion to Greek Religion, Oxford (http://dx.doi. org/10.1002/9780470996911).

Page, D. L. (1981): Further Greek Epigrams, Cambridge (https://doi.org/10.1017/ CBO9780511719998).

Parker, R. (1996): Miasma. Pollution and Purification in early Greek Religion, Oxford.

Pascual, J. (1992): "Las facciones políticas tebanas en el período de formación de la Hegemonía (379-371 a.C.). II: liderazgo y democracia (378-371 a.C.)", Polis. Revista de ideas y formas politicas de antigüedad clásica 4, 187-208.

Peels, S. (2015): Hosios. A Semantic Study of Greek Piety (=Mnemosyne Supplements 387), Leiden (https://doi.org/10.1163/9789004304277).

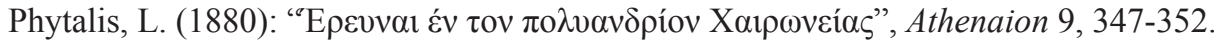

Plassart, A. (1958): "Inscriptions de Thespies", Bulletin de Correspondance Hellénique 82, 107-167 (https://doi.org/10.3406/bch.1958.2337).

Platon, N. -Feyel, M. (1938): “Inventaire sacré de Thespies trouvé a Chostia (Béotie)", Bulletin de Correspondance Hellénique 62, 149-166 (https://doi.org/10.3406/bch.1938.2699).

Pritchett, W. K. (1985): The Greek State at War IV, Berkeley.

Rahe, P. A. (1981): "The Annihilation of the Sacred Band at Chaeronea", American Journal of Archaeology 85, 84-87 (https://doi.org/10.2307/504975).

Ridder, A. de (1922): “Fouilles de Thespies et de l'Hiéron des Muses de l'Hélicon (P. Jamot: 1888-1889-1890, P. Jamot et A. de Ridder: 1891). Monuments figurés", Bulletin de Correspondance Hellénique 46, 217-306 (https://doi.org/10.3406/bch.1922.3035).

Roesch, P. - Darmezin, L. (1983): "Épitaphes de Coronée”, Zeitschrift für Papyrologie und Epigraphik 51, 135-156.

Schachter, A.

(1967): “A Boeotian Cult Type”, Bulletin of the Institute of Classical Studies 14, 1-16 (http://dx.doi.org/10.1111/j.2041-5370.1967.tb00040.x).

(1981): Cults of Boiotia 1: Acheloos to Hera (=BICS Supplement 38.1), London (https:// doi.org/10.1111/j.2041-5370.1981.tb02172.x).

(2003): “Tanagra: The Geographical and Historical Context: Part One”, Pharos 11, 45-74. 
Schilardi, D. (1977): The Thespian Polyandrion (424 BC), PhD. diss., Princeton University.

Selle, H. (2008): Theognis und die Theognidea, Berlin-New York (https://doi. org/10.1515/9783110209648).

Sotiriadis, G. (1903): “Das Schlachtfeld von Chäronea und der Grabhügel der Makedonen”, Mitteilungen des Deutschen Archäologischen Instituts 28, 301-330.

Sourvinou-Inwood, C. (1995): “Reading” Greek Death. To the End of the Classical Period, Oxford.

Stamatakis, $\mathrm{P}$.

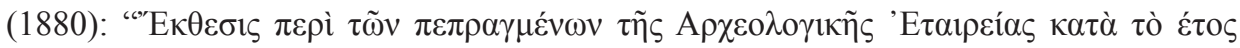

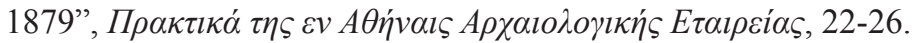

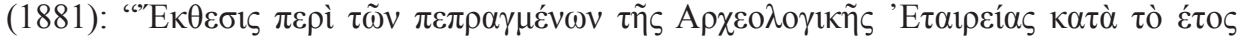

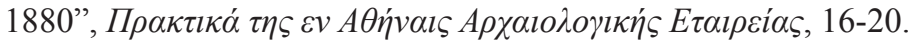

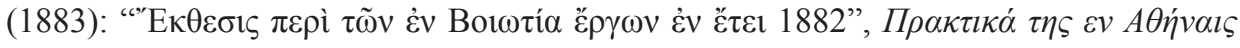

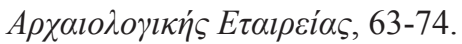

Symeonoglou, S. (1985): The Topography of Thebes from the Bronze Age to Modern Times (=Princeton Legacy Library 415), Princeton.

Taillardat, J. - Roesch, P. (1966): “L'inventaire sacré des Thespies: l'alphabet attique en Béotie", Revue de Philologie 40, 70-87.

Ure, P. N. (1913): Black Glaze Pottery from Rhitsona in Boeotia, London.

Vénencie, J. (1960): "Inscriptions de Tanagra en alphabet épichorique", Bulletin de Correspondance Hellénique 84/2, 589-616 (https://doi.org/10.3406/bch.1960.1570).

Wade-Gery, H. T. (1933): "Classical Epigrams and Epitaphs: A Study of the Kimonian Age", Journal of Hellenic Studies 53/1, 71-104 (https://doi.org/10.2307/627249). 